\title{
Hybrid Metal/Composite Lattice Structures: Design for Additive Manufacturing
}

\author{
Francesco Di Caprio ${ }^{1,+}$, Valerio Acanfora ${ }^{2, *,+}$, Stefania Franchitti ${ }^{1,+}$, Andrea Sellitto ${ }^{2,+}$ (i) \\ and Aniello Riccio ${ }^{2,+} \mathbb{D}$ \\ 1 CIRA-Italian Aerospace Research Centre, 81043 Capua, Italy; f.dicaprio@cira.it (F.D.C.); \\ s.franchitti@cira.it (S.F.) \\ 2 Department of Engineering, University of Campania "L. Vanvitelli", 81031 Aversa, Italy; \\ andrea.sellitto@unicampania.it (A.S.); aniello.riccio@unicampania.it (A.R.) \\ * Correspondence: valerio.acanfora@unicampania.it; Tel.: +39-81-5010407 \\ + These authors contributed equally to this work.
}

Received: 22 March 2019; Accepted: 10 June 2019; Published: 16 June 2019

\begin{abstract}
This paper introduces a numerical tool developed for the design and optimization of axial-symmetrical hybrid composite/metal structures. It is assumed that the defined structures are produced by means of two different processes: Additive Layer Manufacturing (ALM) for the metallic parts and Filament Winding (FW) for the composite parts. The defined optimization procedure involves two specific software: ANSYS and ModeFrontier. The former is dedicated to the production of the geometrical and FE models, to the structural analysis, and to the post-process, focusing on the definition of the Unit Cells for the modelling of the metal part. The latter is dedicated to the definition of the best design set and thus to the optimization flow management. The core of the developed numerical procedure is the routine based on the Ansys Parametric Design Language (APDL), which allows an automatic generation of any geometrical model defined by a generic design set. The developed procedure is able to choose the best design, in terms of structural performance, changing the lattice metallic parameters (number of unit cells and their topology) and the composite parameters (number of plies and their orientation). The introduced numerical tool has been used to design several hybrid structures configurations. These configurations have been analysed in terms of mechanical behaviour under specific boundary conditions and compared to similar conventional metal structure.
\end{abstract}

Keywords: additive manufacturing; lattice structure; hybrid structures; topological optimization

\section{Introduction}

In recent years, the evolution of Additive Manufacturing (AM) towards industrialization has been nothing less than extraordinary, and the field is rapidly growing [1,2].

In particular, in the last thirty years, the AM has experienced double-digit growth, moving from a promising series of technologies not marketed in the early '80s to a market that in 2014 was worth over $\$ 4$ billion. The AM market is projected to grow to over $\$ 21$ billion by 2020 [3-5].

This new family of production technologies, allowing the manufacturing of parts with complex shapes, impossible to be produced by traditional production processes [6-9], plays a key role in the latest industrial revolution (Industry 4.0) which is encouraging the integration of intelligent manufacturing [10-12]. In fact, additive production processes, unlike subtractive manufacturing technologies, produce physical objects, layer by layer, from digital information [13-17]. With this approach, complex geometries such as reticular or porous structures, organic constructions generated 
by topological optimization [18,19], and parts with intricate flow channels [20] are becoming possible and easier to be manufactured.

Engineering design, especially in the aviation industry, is nowadays driven by the pressing demands for:

- reducing fuel consumption and the related contaminant emissions;

- reducing manufacturing costs related to the technologies and materials;

- reducing manufacturing time, enhancing assembly operations and facilitate maintenance of companies.

In order to fulfill such requirements, an increasing use of polymer-matrix composite materials has been observed. This trend has been inevitably followed by a proportional increasing use of Titanium (up to more than $18 \%$ of the total weight of the aircraft), which is the best metallic material candidate to be coupled with carbon fiber reinforced plastic materials, due to the similarity, in terms of thermal expansion coefficient, between titanium and carbon fibers characteristics. Furthermore, galvanic corrosion is avoided coupling titanium and carbon fibers.

Although the hybrid structures are already widely used for structural applications in flat configurations (e.g., sandwich), the demand for hybrid component characterized by more and more complex shapes (three dimensional not axial symmetric geometry) and high performances, makes it necessary to develop new optimization tools able to generate hybrid structures with this characteristics.

In this paper, a numerical procedure is introduced, allowing the modelling in a FE environment and the structural optimization of Hybrid Metal/Composite Lattice Structures [21,22] with very complex shapes which can be seen suitable for Additive Manufacturing technologies.

The Electron Beam Melting (EBM) technology [23-27] has been considered as possible technology to manufacture the metal core, while automatized composite placement technologies, as the filament winding process, has been supposed to be used to manufacture the composite part of the hybrid component. The use of the filament winding process to produce the composite cover, can lead to the restriction of the field of application to axial-symmetric structures. Indeed, the developed routine can produce designs of metal lattice structures with an internal and an external skin. For the application presented in this paper, the internal skin has been supposed to be manufactured in metallic alloy together with the internal lattice structure by adopting additive manufacturing techniques.

Literature methodologies [28-36] use tetrahedral cells in a repetitive configuration generally not able to fit to the external boundaries (the edges of the cells are cut by the body's borders). Further methodologies, implemented in commercial codes, are able to generate other unit cells (cubic, octahedral, etc. [37-40]), but, again, they are not able to fit the shape of complex bodies.

The proposed numerical tool overcomes these limitations being able to manage any type of unit cell and, above all, to fit complex boundaries (both external and internal). The internal lattice generation procedure is very efficient since it very easy to handle and it is not expensive from a computational point of view. Computational efficiency can be very relavant, especially when an optimization analysis has to be performed and thousands of configurations have to be generated and analysed. Finally, the proposed procedure implements the capability to model composite and/or metal skins (internal and/or external) and to consider the layup parameters as further design variables.

The ModeFrontier software has been chosen to manage the optimization process [41,42] by genetic algorithms. The determination of individuals from the initial generation has been chosen by using a sampling type SOBOL, RANDOM and Uniform Latin Hypercube. The optimization algorithm of genetic type MOGA-II has been selected. The design variables of the metallic part are: the number of truss of the basic unit cell; the radius and the length of the basic truss; the number of unit cells; the type and the topologies of the unit cell (connectivity of the cell). For the external skin, the number of plies and their orientation have been defined as design variables. Finally, for the internal (metallic) skin, only the thickness has been selected as design variable. 
One of the strengths of the proposed routine is the perfect connection, at the level of the nodes of the computational grid, between the beam elements of the lattice structure and the shell elements of the skins. This adherence is robust and occurs independently of the geometric complexity of the structure. The shell and beam elements, therefore, will always share a common node at their contact points. Alternatively, this connection could also have been carried out by using contact elements $[43,44]$ leading to a clear modelling simplification, but on the other hand, it would have led both to an increase in calculation times and to a reduction of the accuracy of results.

In Section 2, the calculation routine is briefly described. Then, in Section 3, the techniques of Unit Cells assembly is introduced. In Section 4, the results of the tests carried out on different geometries and under different load conditions, in order to verify the robustness of the routine, are shown. Finally, the results of an optimization loop are reported to verify the perfect integration between the solver and the developed software generating configurations.

\section{Description of the Proposed Routine}

The routine for the generation and the analysis of hybrid metal/composite structures with lattice structure technologies has been generated in APDL language and validated in ANSYS 16.1 and 17.0 environments, while, the release 2014 of the ModeFrontier optimization software has been used.

In this paragraph, the developed procedure has been described, focusing on the options that can be activated to obtain the desired FE models.

The routine is made of 12 main moduli labelled as follows:

- Basic Settings: This modulus contains the commands used to define the graphic options, the definition of the file name, the title to be inserted at the bottom of the window for all the images, and the quality (resolution) of the images generated during the execution of the routine.

- Parameters: This modulus contains all the parameters and the options that allow to create the structure. In order to generate a consistent design, each parameter is allowed to vary in a specific range. An internal check, which enables parameters changing, was implemented to reduce the occurrence of errors. Any automatic changes are recorded on a specific output file (Calculated Parameters section). Other parameters to be defined identify the type of analysis required and the types of load and boundary conditions applied. For a quick classification, in Figure 1 the parameters are catalogued in four macro areas: graphic; unit cell definition; arrangement of unit cells; structure and loads definition.

- Unit Cell Connections: In this modulus, the unit cell connections are defined. Two types of unit cell have been implemented and classified according to the number of internal nodes: 8-node and 27-node. The connection between the nodes is defined by activating a flag ( 1 or 0$)$. The basic numbering for nodes and connections for both cell types are provided below. In this modulus the sequence of flags activating a predefined cell can be defined.

- Calculated Parameters: in this modulus, other parameters useful for the correct sizing of the UCs are evaluated by combining all the parameters previously defined. Moreover, parameters introduced in the previous moduli are checked and, if not consistent, they are overwritten with appropriate values. In addition, at this stage, the matrices associated to the connection flags are compiled. In this modulus, the connections are also redefined according to the symmetric option available for the 27-node unit cells.

- Elements Definition: In this modulus, the element types and the corresponding key-option, used to discretize the numerical model, are defined. Currently, four element types have been implemented:

One-dimensional elements for the discretization of the lattice metal structure;

Layered shell elements for the external skin;

Shell elements for the internal skin;

Rigid elements for the application of particular loading conditions. 
- Materials and Property: This modulus specifies the material properties used for the whole model. The routine supports the modelling of the metal parts by means of linear elastic or elastoplastic, isotropic, and homogeneous material. The composite part (external skin) is modelled with a homogeneous orthotropic (or anisotropic) linear-elastic material. Since the ANSYS code requires the definition of particular sections for the attribution of mechanical and physical properties to the different parts, the sections and their options are also defined at this stage.

- Model Building: At this stage, the routine creates the whole geometrical model. This phase is the heart of the APDL routine. The routine is able to generate any axially symmetric hybrid structures, characterized by different shapes and sizes. Some examples are shown in Figure 2.

\begin{tabular}{|c|c|c|c|}
\hline \multicolumn{4}{|c|}{ PARAMETERS } \\
\hline$\downarrow$ & $\downarrow$ & $\downarrow$ & $\checkmark$ \\
\hline Grafics: & UC definition: & Arrangement of & Structure and loads \\
\hline $\begin{array}{l}\text { Image prel } \\
\text { Image post }\end{array}$ & $\begin{array}{l}\text { UC_sys } \\
U C_{s y s} b\end{array}$ & $\begin{array}{l}\text { UCs: } \\
U C L 1 t h\end{array}$ & stru_rmax \\
\hline Image ucI & UC_adapt & $U C_{-}$Nsys 2 & stru_hmax \\
\hline & UC_bias_rad & numx & Nply \\
\hline & UC bias adp & numy & Thply \\
\hline & UC_Adapt_Cbnd & numz & skin_ext_th \\
\hline & $U C_{-} n n 1$ & & Layup definition \\
\hline & $U C_{-} L 1 x$ & & $\begin{array}{l}\text { skin_int_opt } \\
\text { skin int th }\end{array}$ \\
\hline & $\begin{array}{l}U C_{-} L 1 y \\
U C^{L} L 1 z\end{array}$ & & $\begin{array}{l}\text { Skin_lint_h } \\
\text { Kps for spline surfaces }\end{array}$ \\
\hline & UCRadl & & Mesh \\
\hline & UC $3 x$ Sym & & load \\
\hline & Cel_rint & & Imposed displacement \\
\hline
\end{tabular}

Figure 1. Classification of the parameters used in the routine.
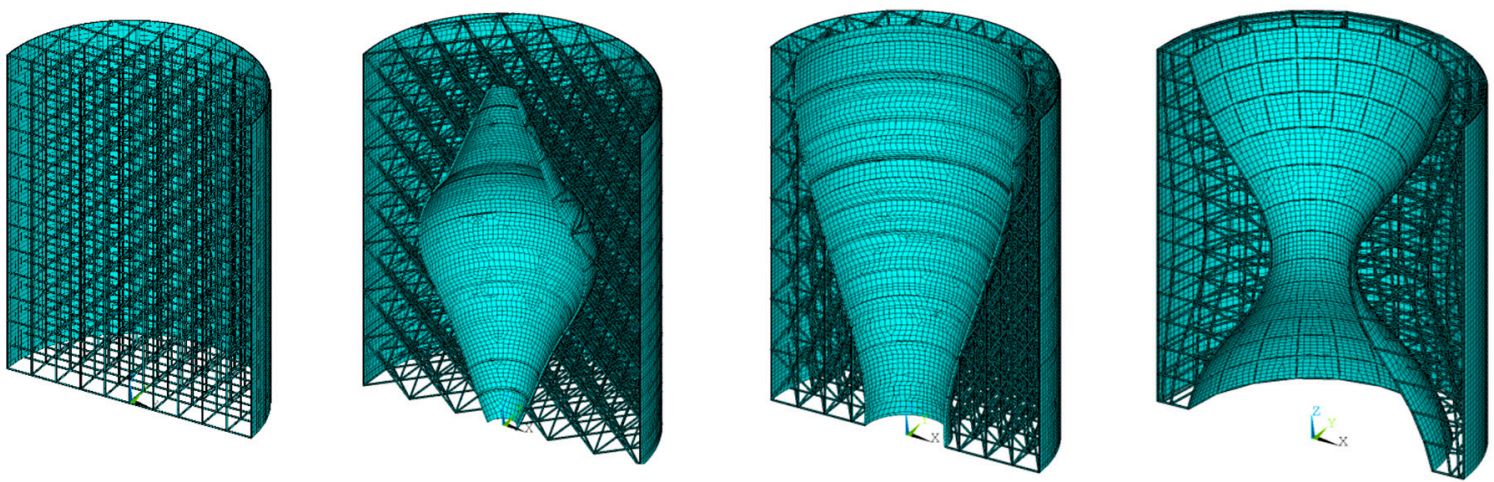

Figure 2. Examples of achievable structures.

The external and internal skins have been defined by surfaces, while the lattice metal structure by lines. A modulus for the automatic generation of images of different views of the model has been implemented as well.

- Meshing: This modulus is dedicated to the mesh generation. Therefore, all the previously created geometries are discretized, according to the specification of the mesh parameters defined in the parameters section.

- Statistics: In this modulus, statistics on the model are performed. In particular, the weight of the whole structure and of each separate part (metal and/or composite), the number of both elements and nodes (of the whole model and of each separate part) are evaluated.

- Boundary Conditions: In this modulus, the desired loading and boundary conditions are applied to the models. Different loading types can be defined, such as compression, traction, bending, torsion, and internal and/or external pressure on both external or internal surfaces.

- Solution: This modulus defines the different types of analysis that can be performed: linear structural analysis, non-linear static analysis (non-linear buckling), and linear buckling analysis. 
- Post-Processing: This modulus is dedicated to the evaluation of the optimization parameters (constraint and objective functions). These parameters are written in an output file, which can be used as input in the ModeFrontier routine. Finally, this modulus includes a specific subroutine used to generate post-processing images.

\section{Unit Cell Definition}

One of the most important aspects of the proposed procedure is the generation of the unit cell which will be used to fill the entire domain. In order to satisfy this requirement, several types of unit cell have been implemented [45-47].

The first selection can be made on the basis of the number of nodes (not to be confused with the nodes of the computational grid). The procedure is able to take into account both 8-node cells and 27-node cells. Since cells with a number of nodes greater than 27 (as an example 64) can be obtained as a combination of cells with 8 and/or 27 nodes, only cells with 8 or 27 nodes have been implemented.

The second selection is related to the construction reference system. The routine, in fact, can construct cells using a Cartesian or cylindrical reference system, thus generating "quadrangular-based prisms" or "cylindrical sectors" respectively.

In Figure 3, a schematization of the different types of the Unit Cells is represented. The unit cylindrical cell allows additional functionality. Indeed, it is possible to define cylindrical cells that can be able to adapt itself to the global structure (i.e., respect to external and internal skin). Once the desired number of adaptive cells, for a given direction, has been defined, they are able to self-adjust the distances between the nodes in that direction using a multiple number of unit cells in order to always have the external nodes of the last cell coincident to the nodes of the outer and inner surfaces.

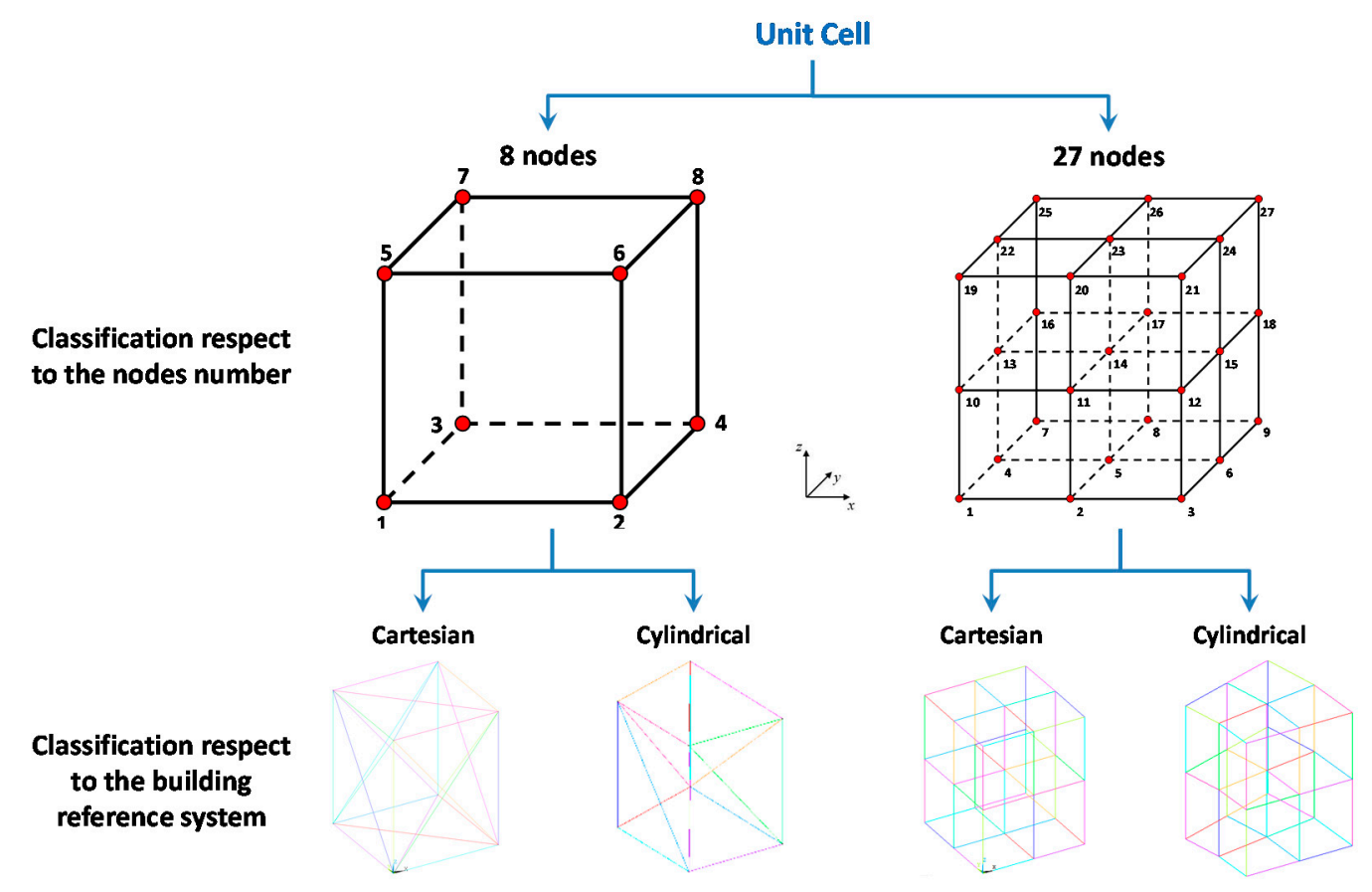

Figure 3. Classification of the Unit Cells.

In addition, by using the cylindrical cells, it is possible to define an automatic bias in radial direction in order to increase the size of the cells as they move away from the axis of revolution of the structure. From the comparison in Figure 4, it is possible to observe the effect of the bias parameter on a configuration with three adaptive cylindrical cells in the radial direction. 

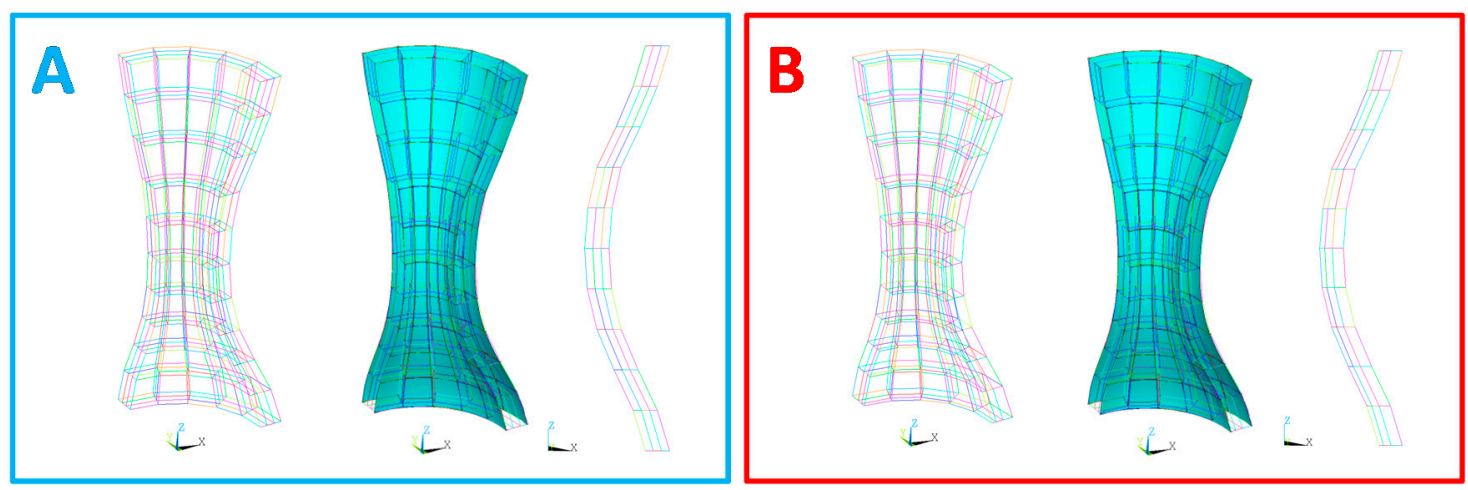

Figure 4. Adaptive cylindrical cell. (A) without radial bias; (B) with radial bias.

Finally, a further option of unit cylindrical cells is the possibility to connect their nodes by means of straight or curved beams. Indeed, curvilinear connections between the nodes can be used to follow the curvature of the global structure. In Figure 5, a comparison between cells with 27 nodes of Cartesian, cylindrical and cylindrical with curvilinear connections (trusses) is shown.
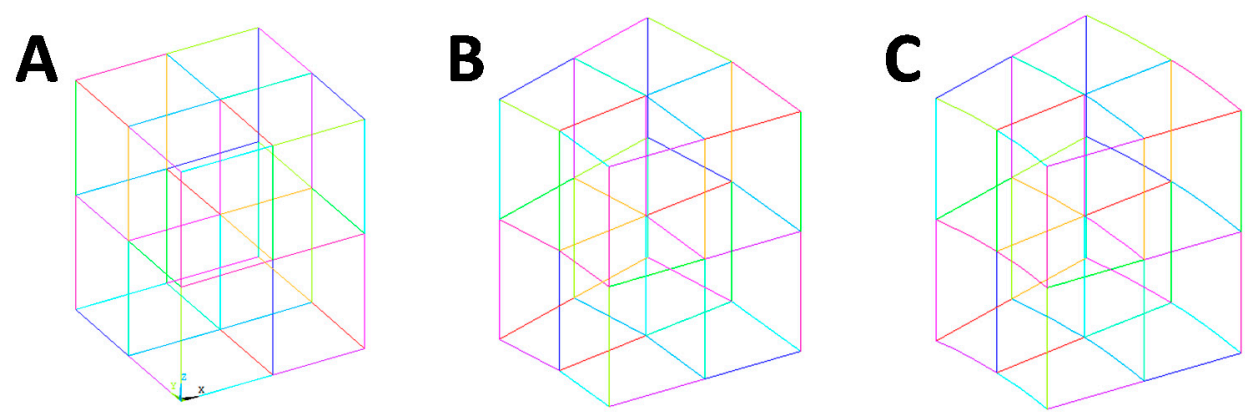

Figure 5. Unit Cells. (A) Cartesian Cell; (B) Cylindrical Cell; (C) Cylindrical Cell with curved trusses.

As shown in Figure 3, each node of the unit cell is associated to a number. This number cannot be modified and it is used to uniquely identify each truss that will be part of the unit cell.

Connections are generated from these nodes. The optimization code will activate or deactivate a specific truss by means of a flag, resulting in the generation of cells with different morphologies. Figure 6 shows the adopted numbering system for the connection elements of an 8-node unit cell.
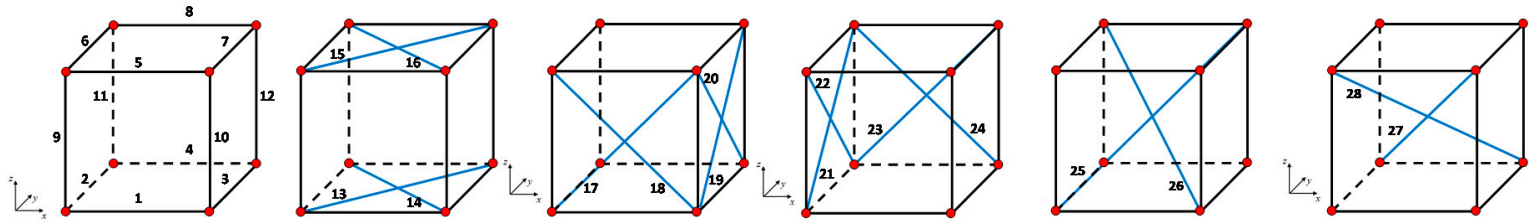

Figure 6. Connection numbering system for 8-node unit cell.

The 27-node cell is divided into eight sub-cells with 8-node, in order to simplify the definition of the connection activation flags. Each sub-cell is based on the same operating logic as the 8-node cell.

A 27-node cell would need the definition of 158 connectivity flags, which would generate an decrease of the computational efficiency. On the other hand, by using the sub-cells method, the user should define $28 \times 8=224$ connections, but, with the same numbering system based on 28 flags, for each sub-cell, letting the code removing any redundant connection. Hence, for each sub-cell the numbering of the connections is identical to the case of an 8-node cell. Figure 7; Figure 8 report the numbering of the sub-cells as implemented in the proposed routine. 

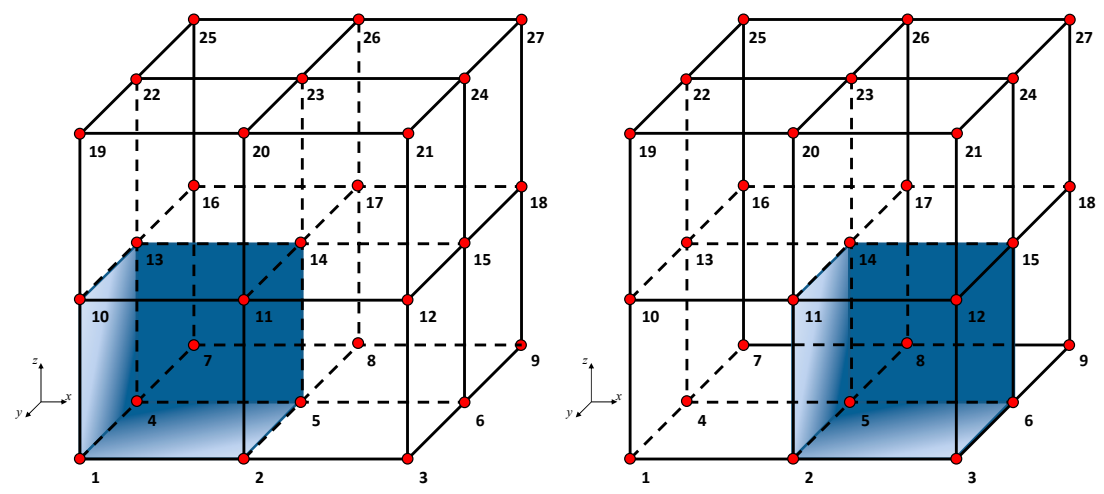

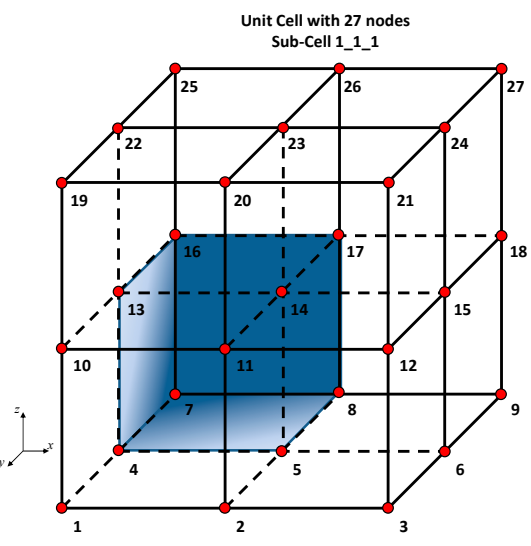

Unit Cell with 27 nodes

nit Cell with 27 nodes
Sub-Cell 2_1_1

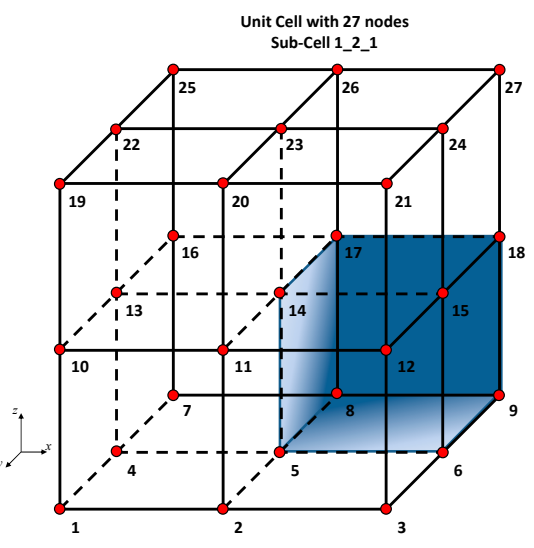

Unit Cell with 27 nodes

Sub-Cell 2_2_1

Figure 7. Connection numbering system for 27-node unit cell-level 1.

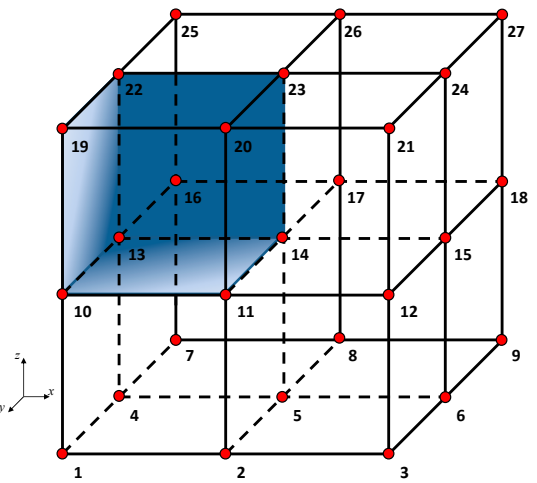

Unit Cell with 27 nodes

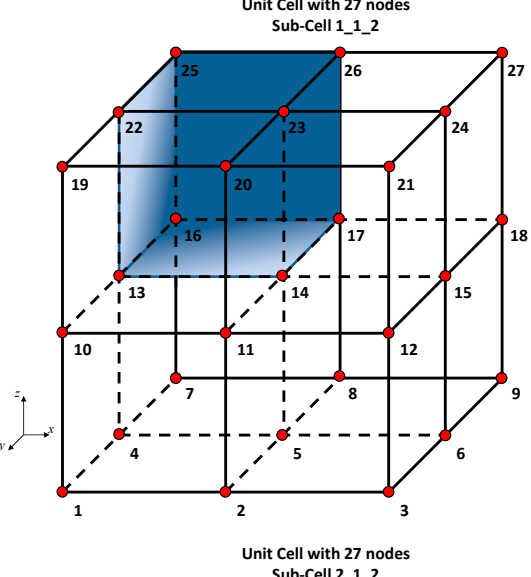

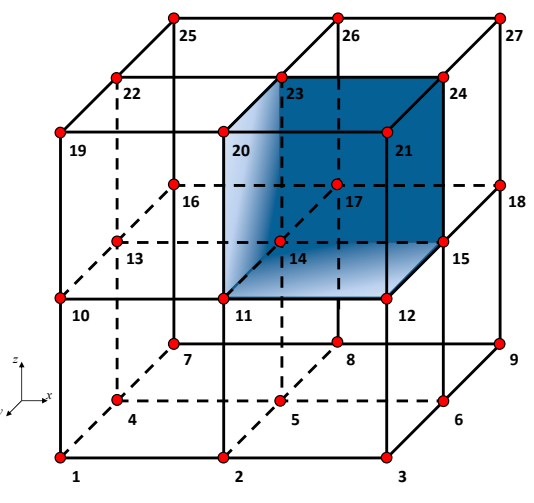

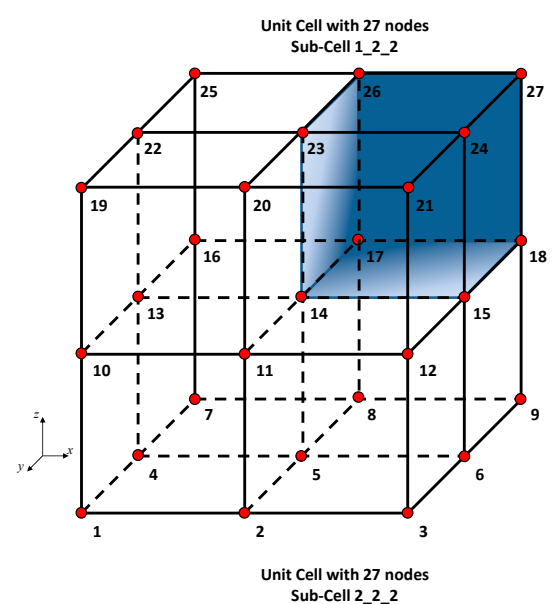

unit cell—level 2. 
In addition, in order to further simplify the connections definition, the symmetrical cell option has been implemented. Obviously, this option, available for 27-node cells only, leads to a reduction of the flag number from 224 to 28 . This simplification aims to decrease the project variables for increasing the efficiency of the optimization procedure.

In order to customize the active connections in a cell, a matrix called "Conect_Nx" has been defined (the matrix Conect_2x defines the connections of 8-node cell while the matrix Conect_3x defines the connections of 27-node cell). These matrices have as number of rows the maximum number of connections available in the unit cell (28) and four columns. In the first column, the connection id is stored; in the second column, a variable indicating the activation status ( $1=$ active or $0=$ not active) of the identified connection is stored. In the third and fourth columns, the connection start and end nodes are listed, respectively. Table 1 is representative of the Conect_Nx matrices.

Table 1. Connectivity Matrix for 8-node cells.

\begin{tabular}{cccc}
\hline Connection ID & $\begin{array}{c}\text { Connection Flag } \\
\text { 0 = Not Active } \\
\text { 1 = Active }\end{array}$ & Node $\mathbf{1}$ & Node 2 \\
\hline 1 & 1 & 1 & 2 \\
2 & 0 & 1 & 3 \\
3 & 1 & 2 & 4 \\
$\ldots$ & $\ldots$ & $\ldots$ & $\ldots$ \\
28 & 0 & 4 & 8 \\
\hline
\end{tabular}

Figure 9 shows a portion of the routine, where the flags for an 8-node cell are defined. As said previously, 28 possible connections for this type of cell exists, requiring the definition of 28 parameters with a value of 1 or 0 .

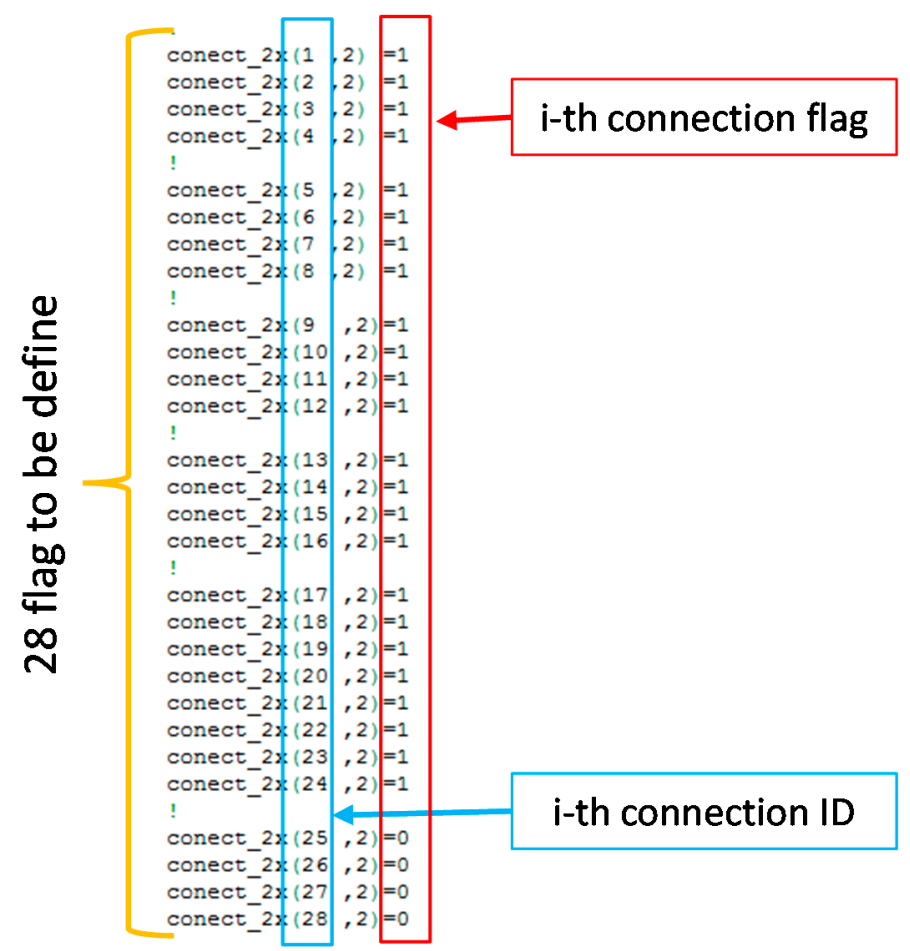

Figure 9. Flag definition for Unit Cell connection. 


\section{Numerical Results}

The internal and external skins are created through the revolution around the axis of the structure of splines (a spline for internal skin and another for external skin) that interpolate several control points. Both the internal and external skins can be created separately.

With this methodology it is possible to generate several types of axial symmetrical structures, all with a strong coupling between lattice structure and skin at the level of the nodes of the computational grid. Hence, regardless the type of internal lattice structure and regardless of the geometry of the skins, there will be shared nodes between the shell elements (skin) and beam elements (lattice structure). This kind of connection could also have been made with contact elements. This would have led to a clear simplification of the procedure for the construction of the structure, but, on the other hand, it would have led to an increase in computational time and to less accurate results.

Therefore, in order to verify the robustness of the procedure in generating differently shaped complex structures representative of the mechanical behaviour of lattice metallic structures with composite and metallic skins, tests were carried out on different configurations, under different loading and boundary conditions. Finally, the results of an optimization loop are reported to verify the perfect integration with the chosen optimization software.

\subsection{Test Case 1}

In order to verify both the robustness of the proposed routine in the pre-processing, setting and post-processing of linear and nonlinear analyses, and to verify the onset of global instabilities, in the frame of the Test Case 1, a linear buckling analysis and, subsequently, a nonlinear static analysis have been performed.

As shown in Figure 10, the chosen structure is a conical trunk sector with a $1 \mathrm{~mm}$ metal internal skin and a $1 \mathrm{~mm}$ composite external skin with a stacking sequence of $[45 ;-45]_{2}$.

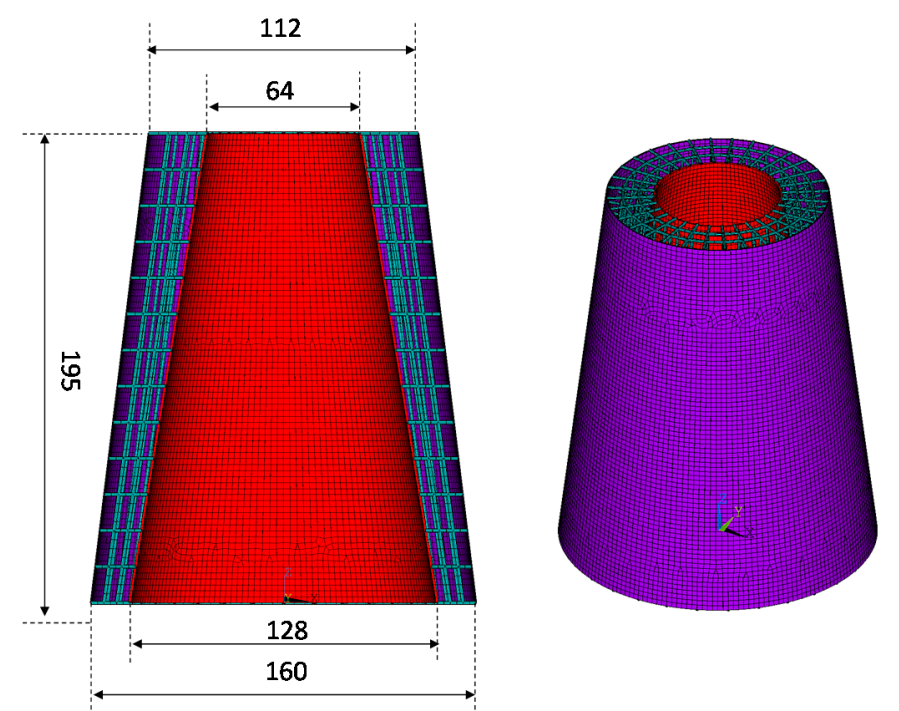

Figure 10. Test case 1-FE model.

For this structure, an 8-node adaptive cell without bias factor has been used. The cell has only 12 connections, represented by the edges of the cell, neglecting the diagonal connections.

Figure 11 shows the used elementary cell and a quarter of the latex structure. 


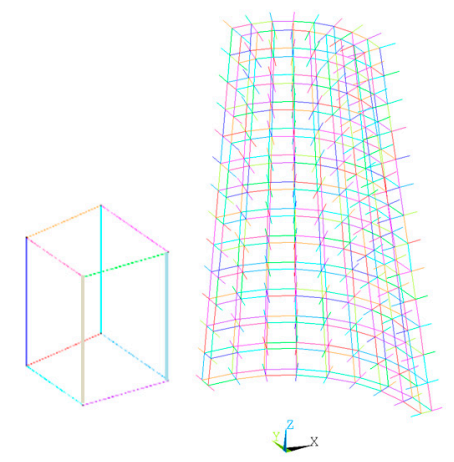

Figure 11. Unit Cell and cells of the 1st quarter.

The structure has been subjected to a compressive loading condition in order to evaluate the buckling load by a linear buckling analysis and a static non-linear buckling analysis.

Figures 12 and 13 show the nodal displacements (eigenvector) for at the first calculated buckling load (eigenvalue) and highlights that instability involves both the skins and the internal lattice structure. Actually, for both the components, local buckling modes have been found with no real global instability able to compromise the structure carrying loading capability.
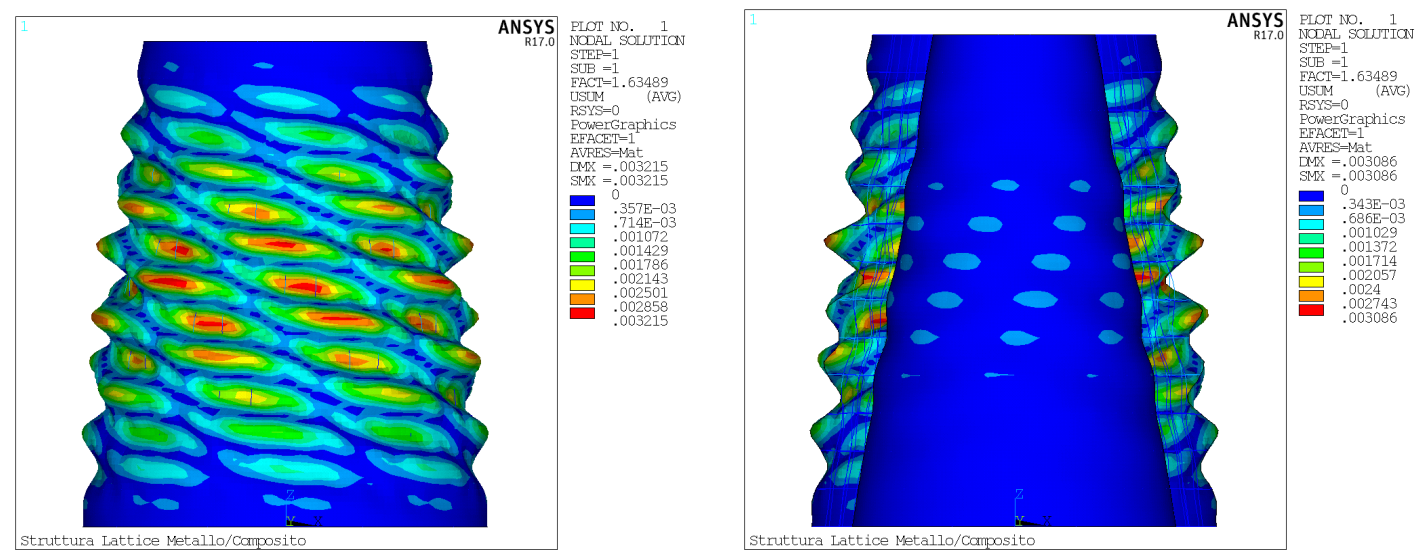

Figure 12. Test case 1-1st buckling mode-Total Displacement.
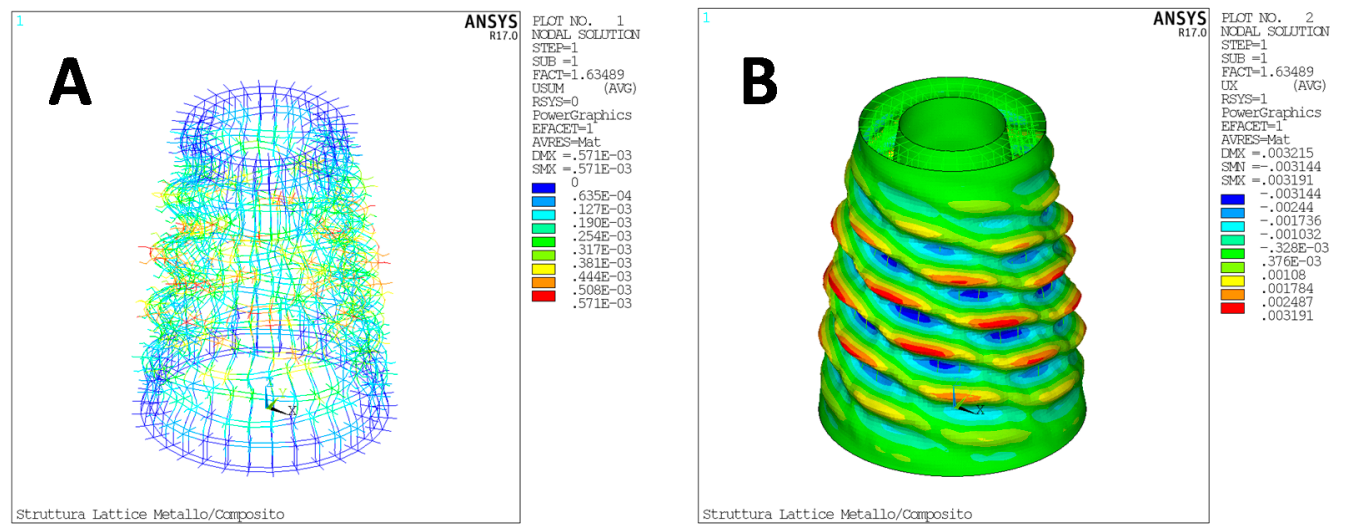

Figure 13. Test case 1-1st buckling mode. (A) Total Displacement in Cartesian reference system; (B) radial displacement in cylindrical reference system.

The mass properties of the structure are reported in Table 2. 
Table 2. Test case 1-Mass budget.

\begin{tabular}{cccc}
\hline Lattice Mass & External Skin Mass & Internal Skin Mass & Total Mass \\
\hline $0.246(\mathrm{~kg})$ & $0.099(\mathrm{~kg})$ & $0.262(\mathrm{~kg})$ & $0.609(\mathrm{~kg})$ \\
\hline
\end{tabular}

The first eigenvalue is 1.63 , and since a unit compression displacement has been applied, it is possible to quantify a critical compressive displacement of $1.63 \mathrm{~mm}$. The equivalent critical compressive load is $394.02 \mathrm{kN}$. Figures 14-16 show the nodal displacements (eigenvectors) for subsequent modes (not consecutive) which can be classified as local buckling modes too.
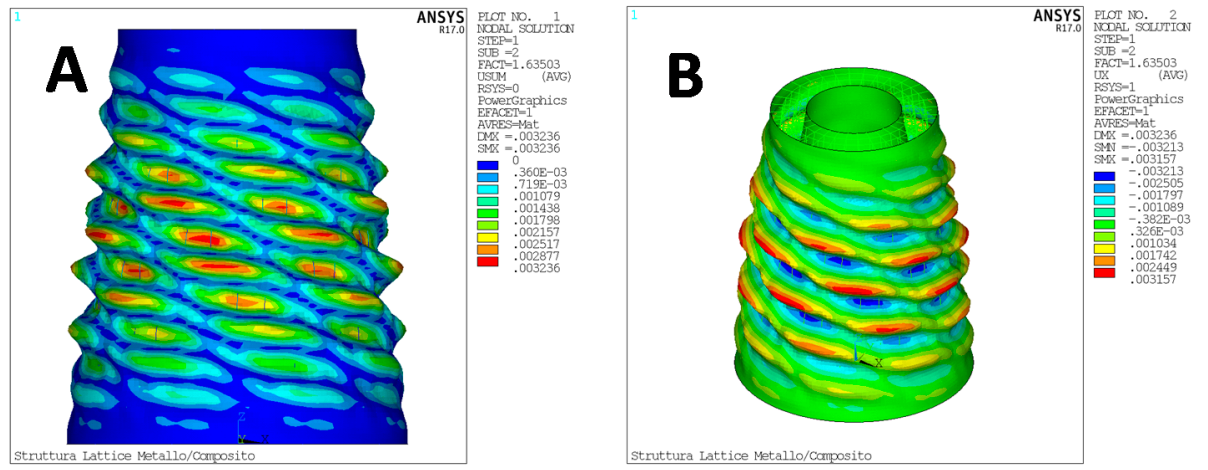

Figure 14. Test case 1-2nd buckling mode. (A) Total Displacement in Cartesian reference system; (B) radial displacement in cylindrical reference system.
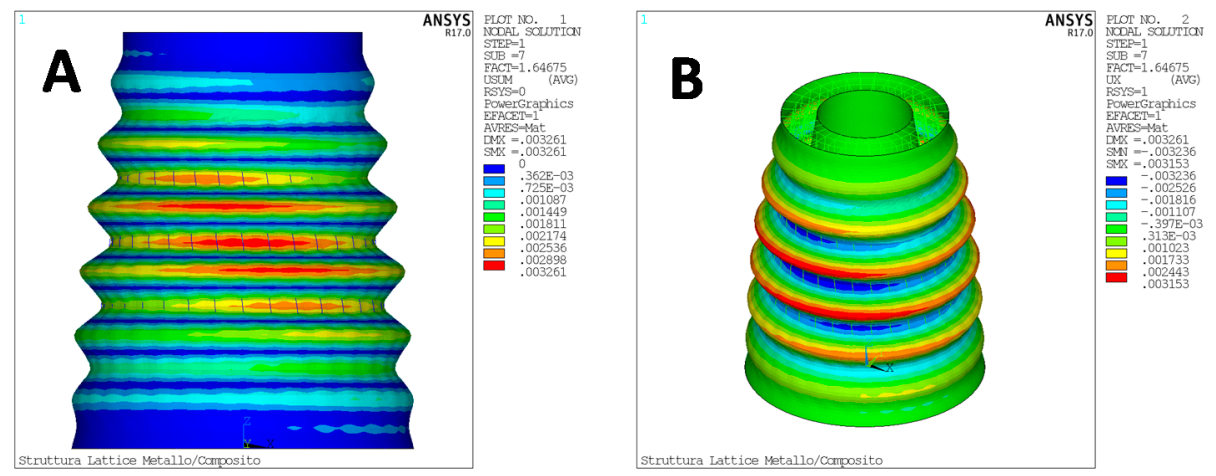

Figure 15. Test case $1-7$ th buckling mode. (A) Total Displacement in Cartesian reference system; (B) radial displacement in cylindrical reference system.
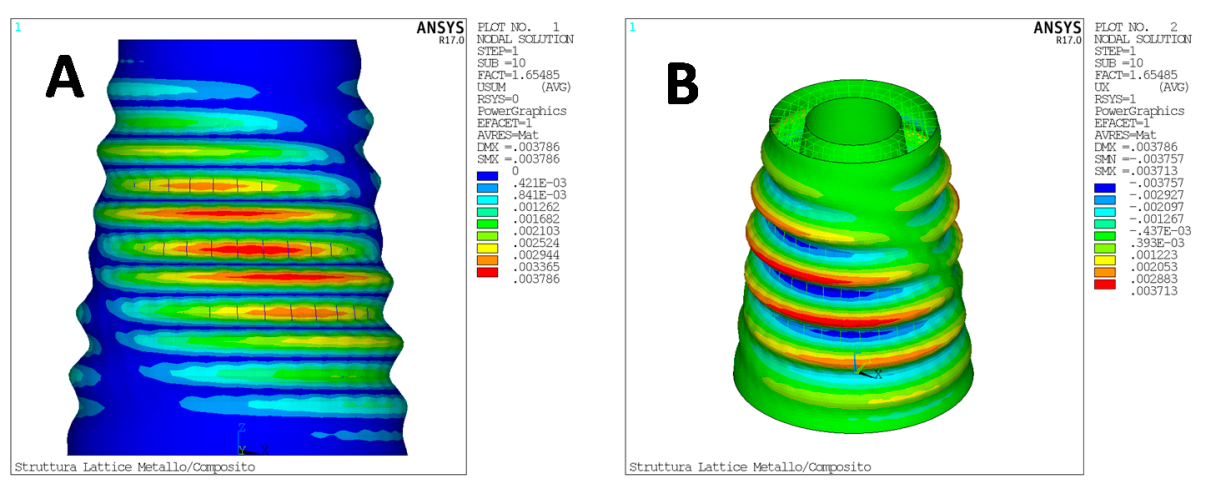

Figure 16. Test case 1-10th buckling mode. (A) Total Displacement in Cartesian reference system; (B) radial displacement in cylindrical reference system.

According to Figures 14-16, it can be noted that the first 10 eigenvalues are very close each other. 
The outputs shown are only a small part of those made available by the downstream routine of the analysis, moreover at the end of the analysis, the routine provides a practical text file that contains all the data of interest for the analysis.

Then, a static non-linear analysis, considering the geometric non-linearities, has been performed in order to compare the linear and non-linear buckling load. The results, in terms of load-displacement and stiffness-displacement curves, are reported in Figure 17.
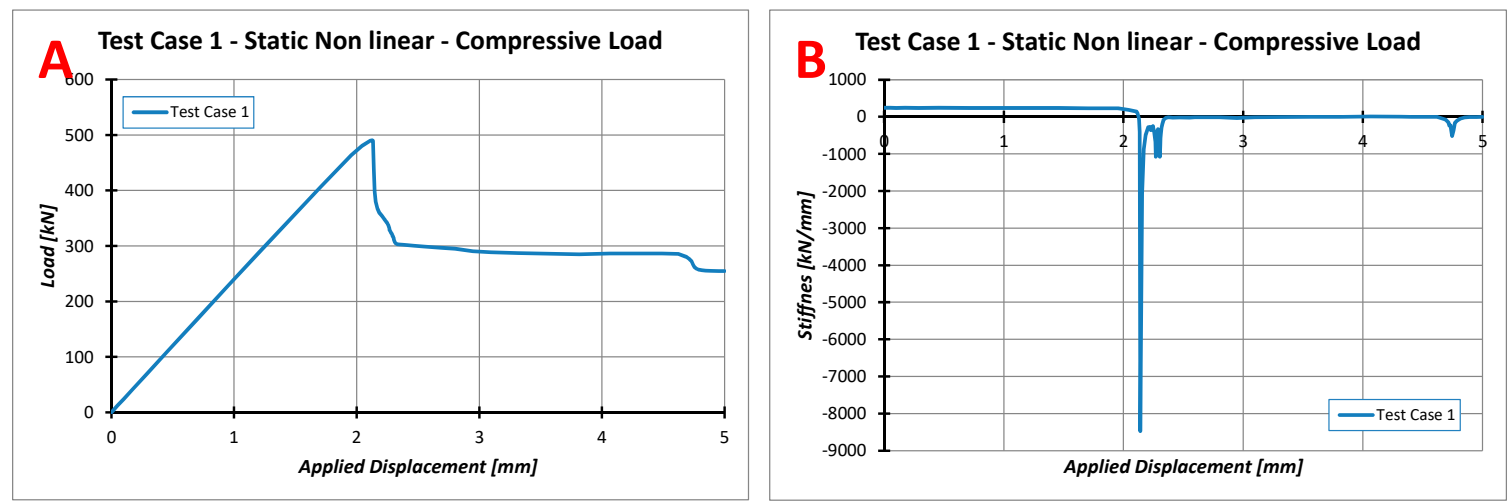

Figure 17. Test case 1-Non-linear analysis. (A) Load—displacement curve. (B) Stiffness—displacement curve.

As it can be seen from Figure 17, the global buckling load is around $490 \mathrm{kN}$ with an imposed displacement of about $2.1 \mathrm{~mm}$. Thus, the structure, once the local instabilities have been detected, can tolerate an additional $25 \%$ load before the global instability with the consequent loss of its ability to support further compressive load.

This may suggest that this type of structure could also be considered as safe when the instability load of the individual internal units is exceeded. Figure 18 shows the global displacements corresponding to the critical compressive displacement.
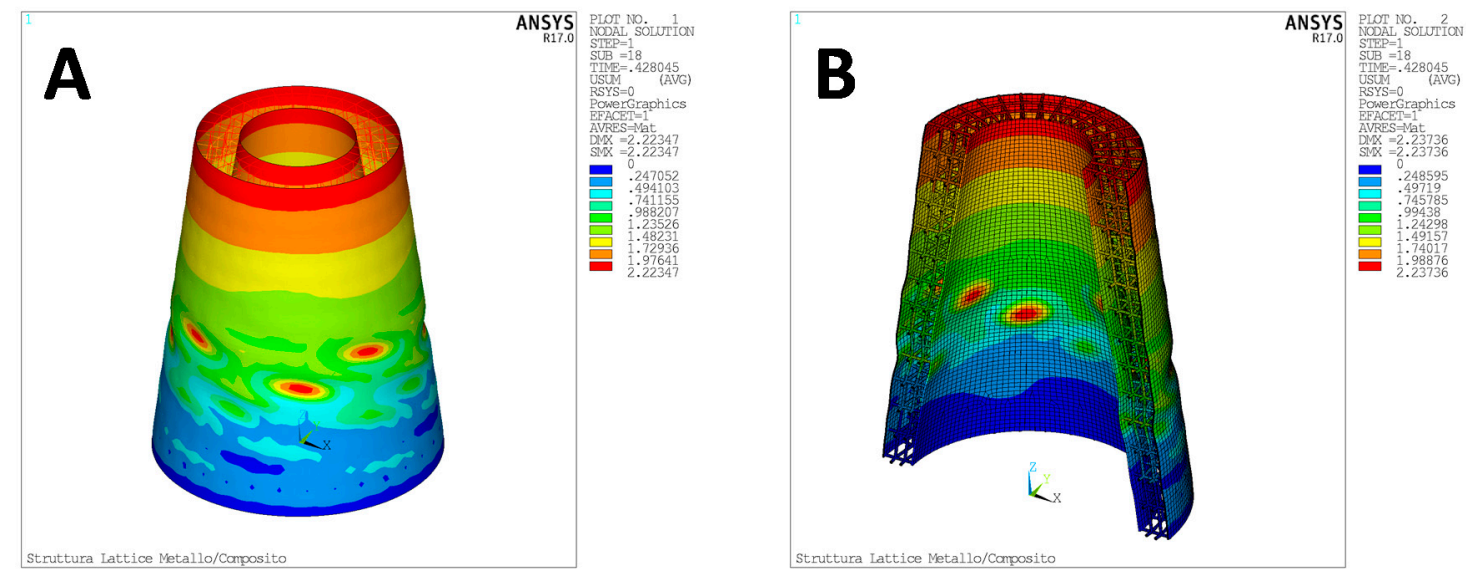

Figure 18. Test case $1-$ Non-linear analysis—-total displacement at critical compressive load.

\subsection{Test Case 2}

The second test case consists of an axial symmetrical cylindrical structure. The structure has been subjected to both linear buckling analysis and non-linear static analysis. The applied load generates a state of global compression in the structure. Figure 19 shows the analysed structure, its geometry, and the boundary conditions set for the analysis. 

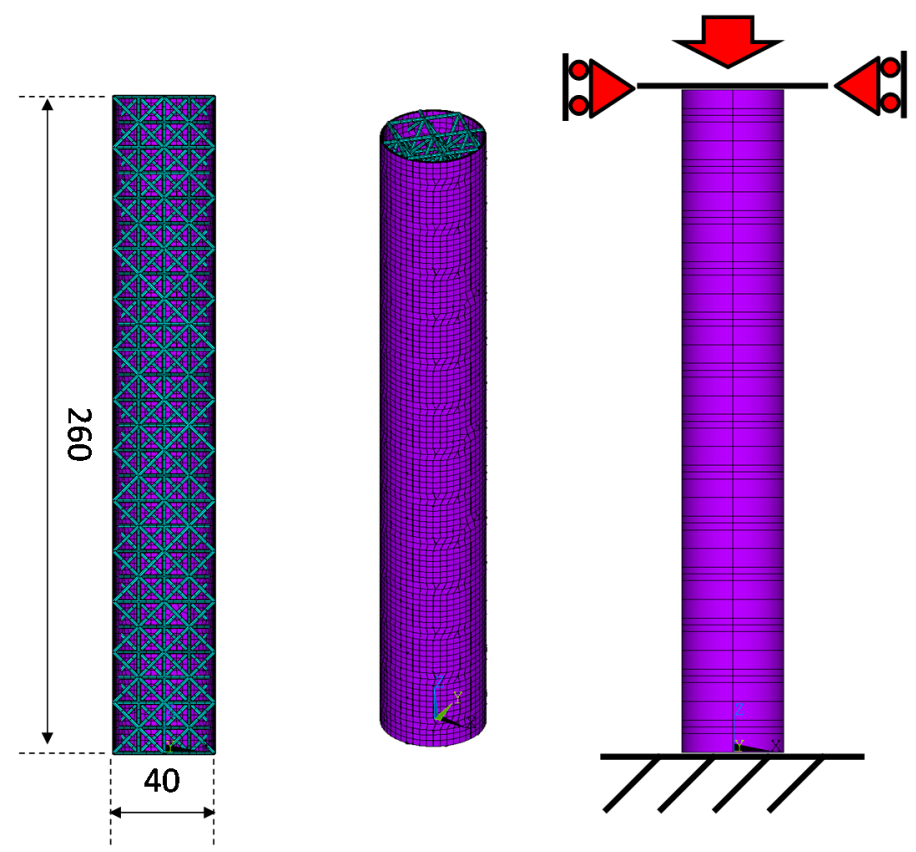

Figure 19. Test case $2-$ Geometry and boundary conditions.

A 27-node Cartesian Cell has been used for this structure. The cell has 36 connections and it is classified as regular octahedral. The structure does not have an internal skin, while the stacking sequence of the external skin is $[45 ;-45]_{3}$. Figure 20 shows the adopted elementary cell and a quarter of the global lattice structure.

As for Test Case 1, the structure has been subjected to a compressive loading condition in order to verify its instability threshold. Two different analyses have been carried out: linear buckling and static non-linear analysis. Figure 21; Figure 22 show the nodal displacements (eigenvector) for the first calculated buckling load (eigenvalue). It is clear that the instability only involves the internal structure. Also for this component, it should be noted that these are local modes, so the structure's ability to withstand further load increases has not been compromised.

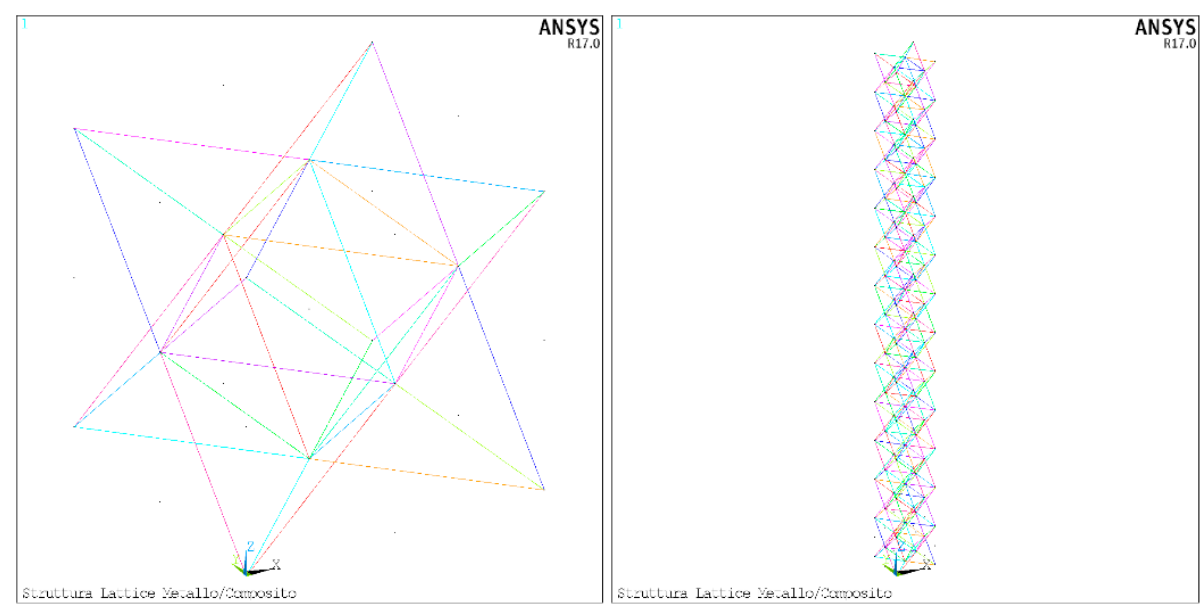

Figure 20. Test case 2-octahedral unit cell and 1st quarter. 


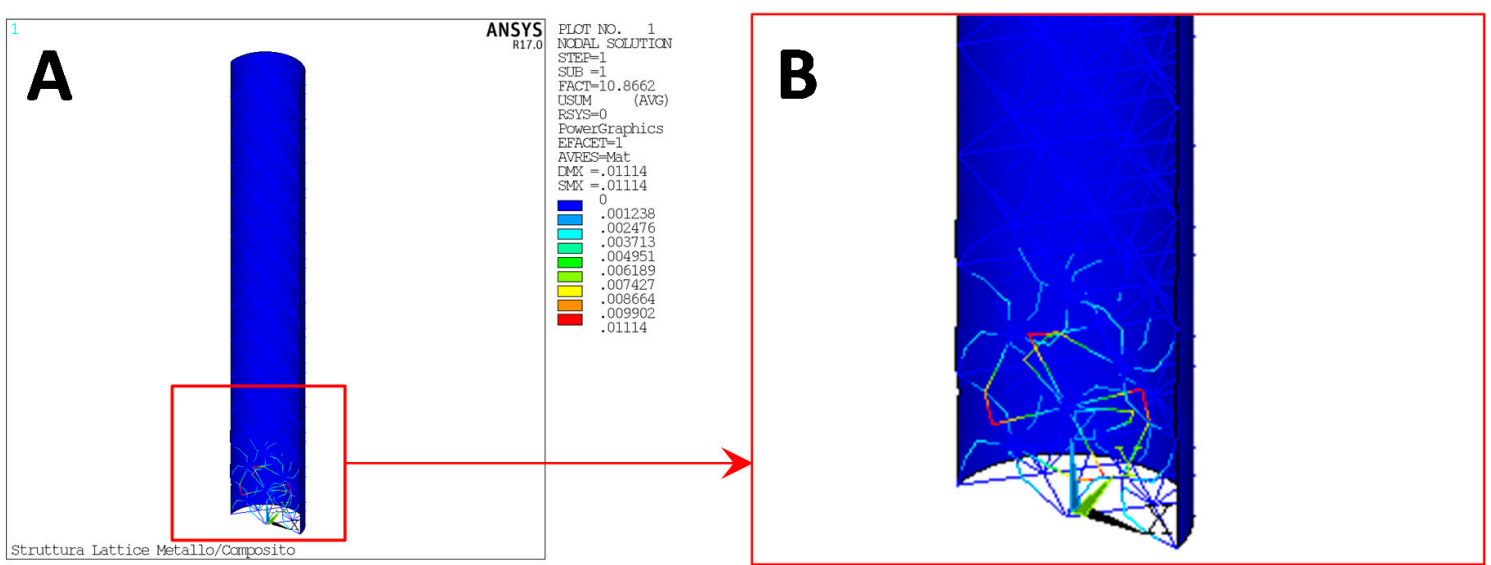

Figure 21. Test case 2-1st buckling mode. Total Displacement: entire model (A) and detail (B).
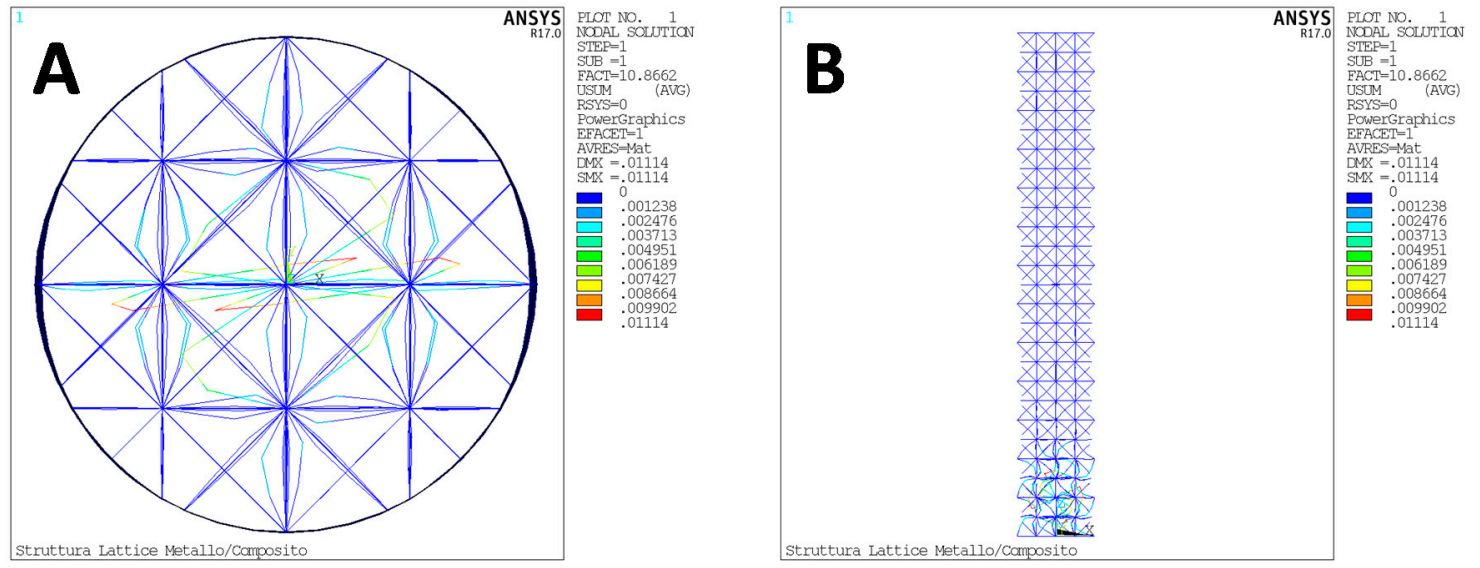

Figure 22. Test case 2-1st buckling mode. Total Displacement: upper view (A) and lateral view without skin (B).

The mass properties of the structure are listed in Table 3.

Table 3. Test case 2-Mass budget.

\begin{tabular}{cccc}
\hline Lattice Mass & External Skin Mass & Internal Skin Mass & Total Mass \\
\hline $0.098(\mathrm{~kg})$ & $0.058(\mathrm{~kg})$ & N/A & $0.157(\mathrm{~kg})$ \\
\hline
\end{tabular}

The first eigenvalue is 10.86 and, since a unit compression displacement has been applied, it is possible to quantify the critical displacement in $10.86 \mathrm{~mm}$, which is equivalent to a compressive load of $139.93 \mathrm{kN}$. Figure 23 shows the load-displacement and stiffness-displacement curve of the non-linear static analysis.

As can be seen from Figure 23, the global buckling load with an imposed displacement of about $12.7 \mathrm{~mm}$ is over $162 \mathrm{kN}$. Therefore, the structure can tolerate an additional $15 \%$ of load before the global instability and the loss of its ability to sustain further compression load. Figure 24; Figure 25 show the radial (according to the cylindrical coordinate system) and the total displacement at two different time steps representative, respectively, of the local buckling and global buckling conditions. 

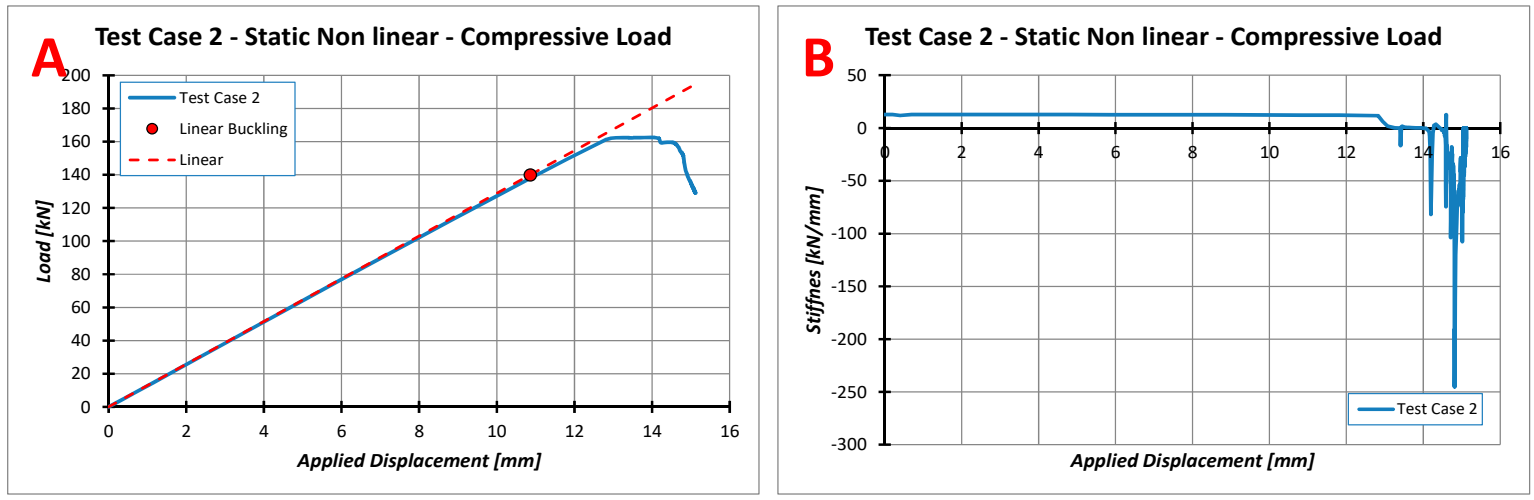

Figure 23. Test case 2-Non-linear analysis. (A) Load—displacement curve; (B) stiffness—displacement curve.
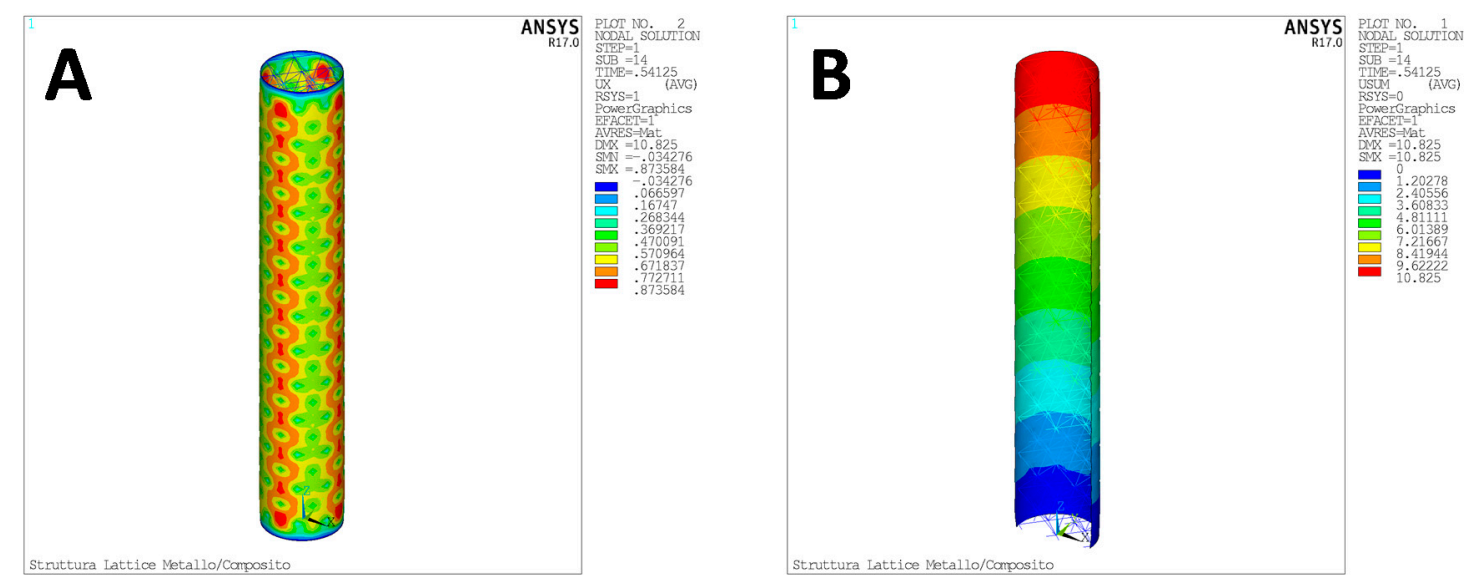

Figure 24. Test case $2-$ Non-linear analysis. Radial displacement (A) and total displacement (B) at local buckling.

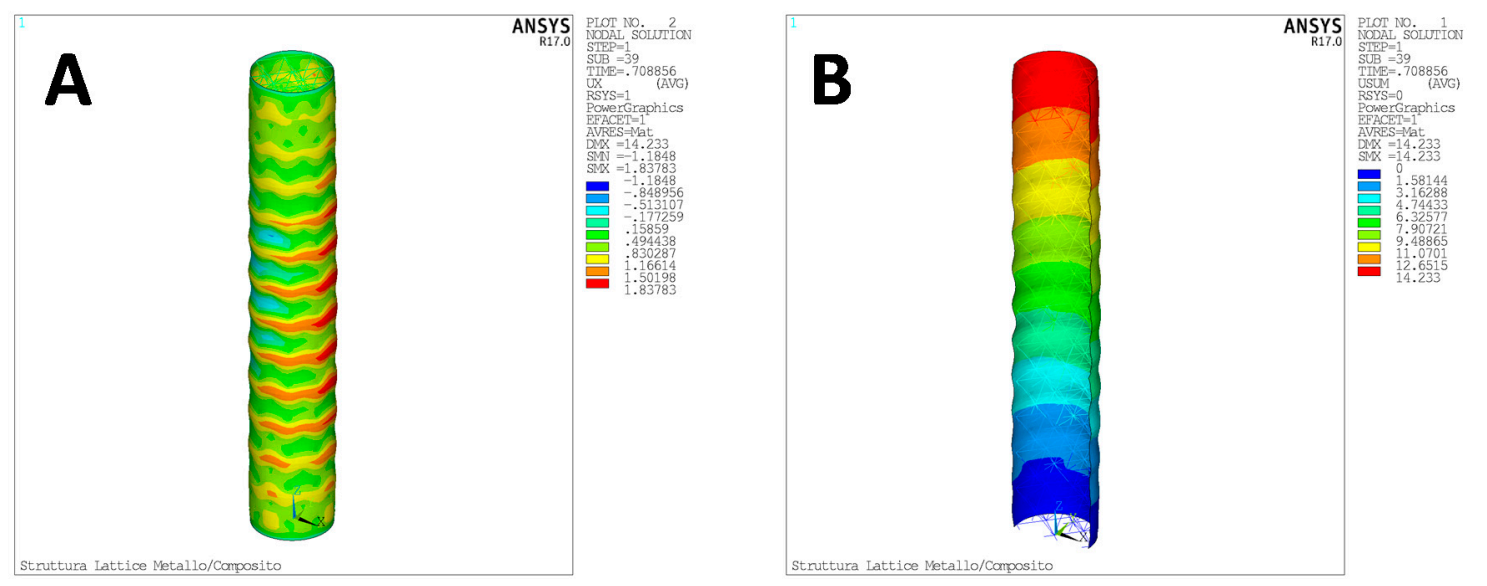

Figure 25. Test case $2-$ Non-linear analysis. Radial displacement (A) and total displacement (B) at global buckling.

\subsection{Test Case 3-Structural Optimization}

The last test case is focused on the optimization of a cylindrical lattice structure with internal skin in metal and external skin in composite material.

To maximize the efficiency of the optimization phase and thus to reduce the computational costs, a reduced set of design variables has been set for this case. The structure has been optimized in terms of weight. As constraint function, the buckling load must be higher than $140 \mathrm{kN}$ (which is the 
buckling load of test case 2). Therefore, only linear buckling analyses have been performed, and the first buckling load has been used to evaluate the feasibility (or unfeasibility) of a solution.

In this specific case, the design variable reported in Table 4 have been taken into account.

Table 4. Design variables.

\begin{tabular}{ccccccc}
\hline UC_RAD1 & UC_L1z & UC_L1TH & UC_NSYS2 & NPLY & SKIN_INT_TH & $\begin{array}{c}\text { Connect_2X } \\
\text { Matrix }\end{array}$ \\
\hline $\begin{array}{c}\text { radius single } \\
\text { connecting } \\
\text { element }\end{array}$ & $\begin{array}{c}\text { cell size in axial } \\
\text { direction }\end{array}$ & $\begin{array}{c}\mathrm{N}^{\circ} \text { of cells in } \\
\text { tangential } \\
\text { direction }\end{array}$ & $\begin{array}{c}\mathrm{N}^{\circ} \text { of cells in the } \\
\text { thickness } \\
\text { (between internal } \\
\text { and external skin) }\end{array}$ & $\begin{array}{c}\mathrm{N}^{\circ} \text { of ply of } \\
\text { external skin }\end{array}$ & $\begin{array}{c}\text { thickness of } \\
\text { metallic } \\
\text { internal skin }\end{array}$ & $\begin{array}{c}28 \text { connection } \\
\text { flags for 8-node } \\
\text { cell. }\end{array}$ \\
\hline
\end{tabular}

For the entire optimization run, an 8-node cylindrical adaptive cell has been considered without radial bias factor. Since this is a linear buckling analysis which is not able to provide in output a stress state, the minimum buckling load of $140 \mathrm{kN}$ has been set as the only constraint function.

The objective function is represented by the total mass of the structure.

The generation 0 (the initial one) has been created by a SOBOL algorithm with 200 individuals. The optimization algorithm is a MOGA-II with 100 generations characterized by the set of parameters listed in Figure 26.

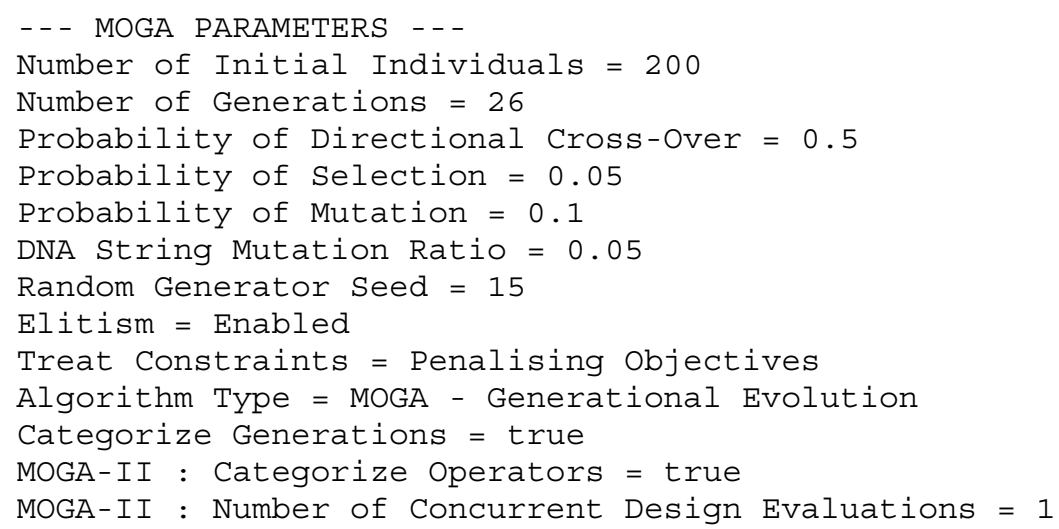

Figure 26. Optimization parameters.

5200 individuals has been evaluated during the optimization run. The best design has been evaluated at configuration 3130 and it is characterized by the mass properties reported in Table 5 .

Table 5. Test case 3-Mass budget.

\begin{tabular}{cccc}
\hline Lattice Mass & External Skin Mass & Internal Skin Mass & Total Mass \\
\hline $0.011(\mathrm{~kg})$ & $0.038(\mathrm{~kg})$ & $0.043(\mathrm{~kg})$ & $0.0936(\mathrm{~kg})$ \\
\hline
\end{tabular}

Figure 27 shows the percentage of feasible and infeasible individuals, and the percentage of individuals that the software failed to analyse. Indeed, some individuals can results in non-consistent structures; for example, in the case in which all flags of the cell connections are set equal to 0 .

As it is possible to notice, the feasible design set is over $77 \%$, followed by $20 \%$ of unfeasible individuals, and almost $3 \%$ of individuals not evaluated.

Hereafter, the results of the analyses carried out on the best design set are introduced. Figure 28 shows the analysed structure, with its geometry and the boundary conditions set for the analysis. 


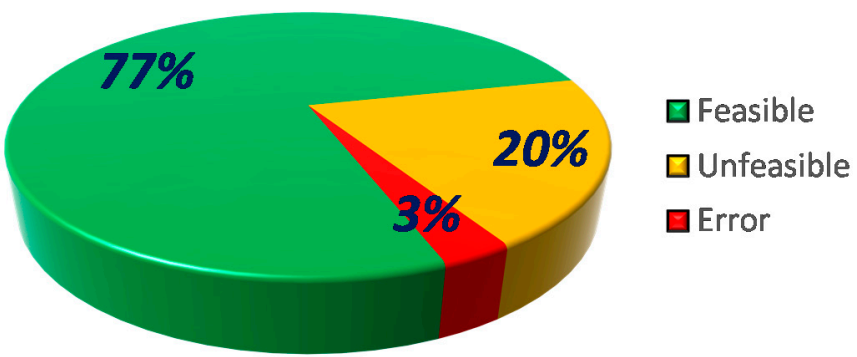

Figure 27. Feasible, unfeasible, and failed individuals.
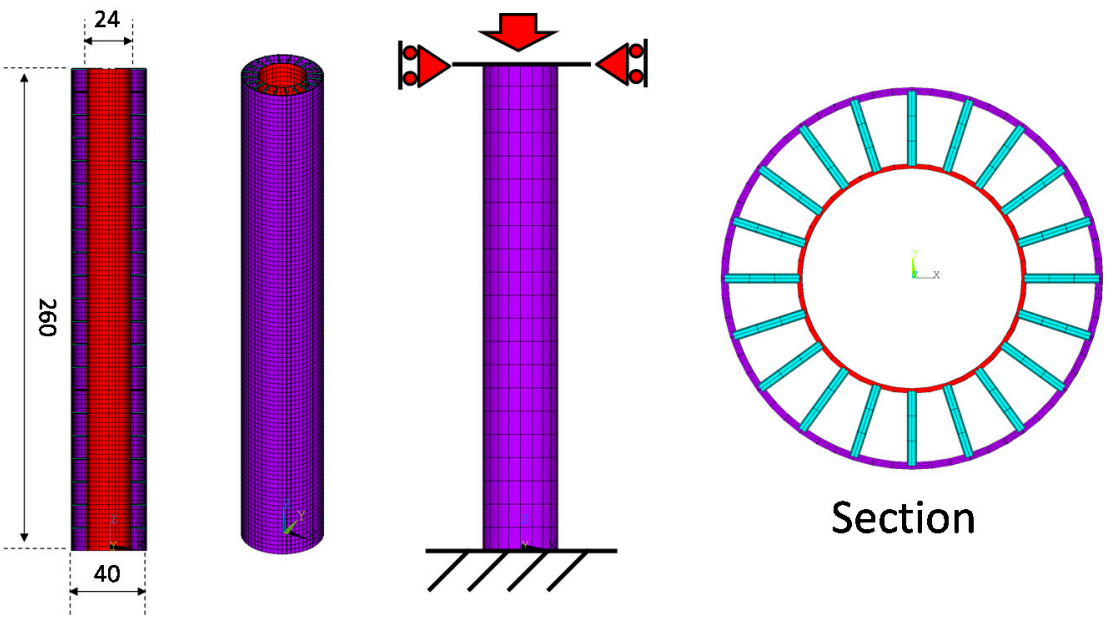

Section

Figure 28. Test Case 3-Best design—Geometry e boundary conditions.

For this structure an adaptive cylindrical cell with 8-node and 4 connections has been used. The diameter of each element of the latex structure is $0.5 \mathrm{~mm}$. The structure has an internal skin with a thickness of $0.5 \mathrm{~mm}$, and the external skin is characterized by 4 plies with the segmented stacking sequence of $[45 ;-45]_{2}$.

Figure 29; Figure 30 show the total nodal displacements (eigenvector) for the first calculated buckling load (eigenvalue). The instability involves only the internal structure and the internal skin. For this component, only local instability modes have been detected.

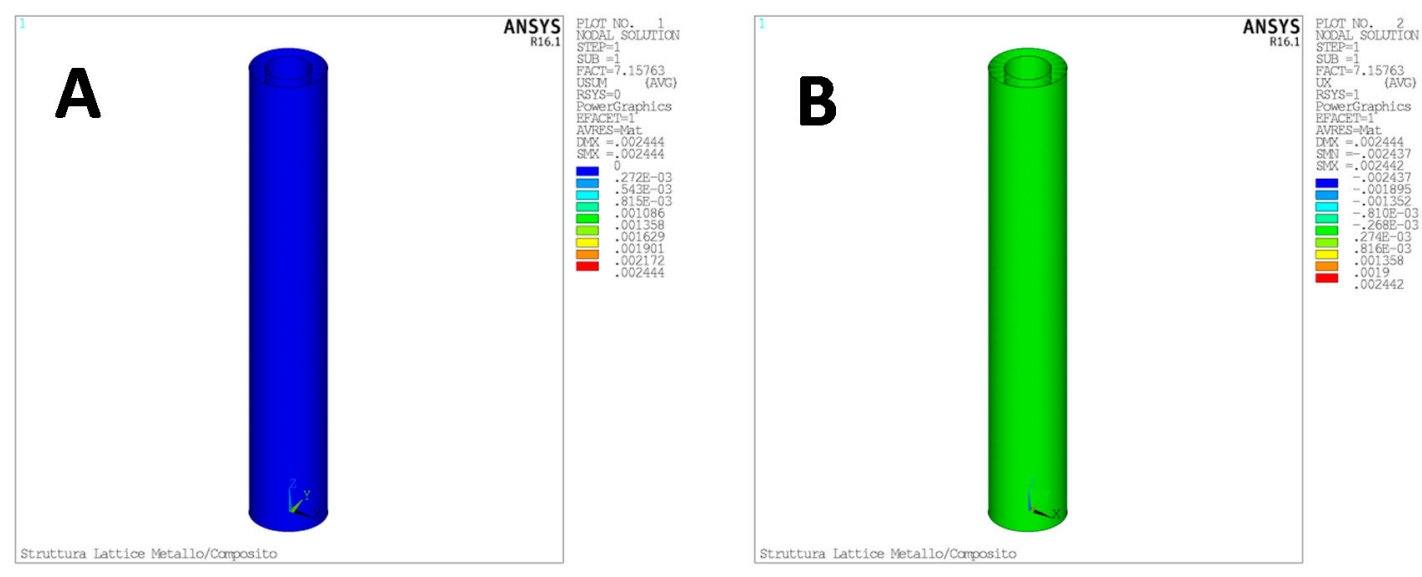

Figure 29. Test Case 3-1st buckling mode. (A) Total Displacement in Cartesian reference system; (B) radial displacement in cylindrical reference system. 


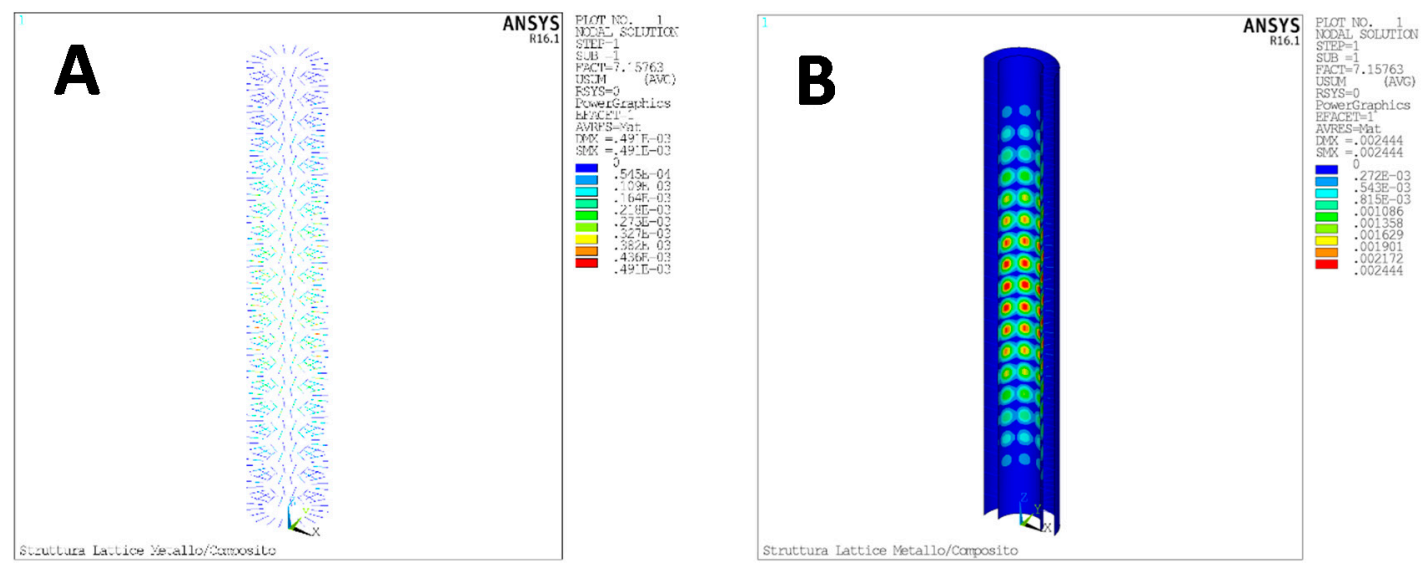

Figure 30. Test Case 3-1st buckling mode-Total Displacement. (A) only lattice structure; (B) only internal and external skins.

The first eigenvalue is 7.15, and, having applied a unit compression displacement, it is possible to quantify the critical displacement in $7.15 \mathrm{~mm}$, corresponding to a critical load of $143 \mathrm{kN}$.

It should be noted that this structure has improved performances if compared to a generic solid structure. Indeed, considering a beam structure with cylindrical section and the same material, it is possible to estimate the critical load with the Euler formula. Table 6 shows the data of a solid structure with similar structural performances, i.e., with a critical load equal to $143 \mathrm{kN}$. The mass for such a structure is $0.208 \mathrm{~kg}$.

Considering, therefore, that the total mass of the optimized lattice/skins structure is $0.093 \mathrm{~kg}$, it is possible to quantify an achieved mass reduction of more than $55 \%$.

Table 6. Buckling load of reference solid structure.

\begin{tabular}{ccccccccc}
\hline $\begin{array}{c}\text { Section } \\
\text { Radius } \\
(\mathbf{m m})\end{array}$ & $\begin{array}{c}\text { Section } \\
\text { Diameter } \\
(\mathbf{m m})\end{array}$ & $\begin{array}{c}\text { Inertia } \\
\text { Section } \\
\left(\mathbf{m m}^{\mathbf{4}}\right)\end{array}$ & $\begin{array}{c}\text { Length } \\
\mathbf{( m m )}\end{array}$ & $\begin{array}{c}\text { Young's } \\
\text { Module } \\
\mathbf{( M P a})\end{array}$ & $\begin{array}{c}\text { Density } \\
\left(\mathbf{T o n} / \mathbf{m m}^{\mathbf{3}}\right)\end{array}$ & $\begin{array}{c}\text { Volume } \\
\left(\mathbf{m m}^{\mathbf{3}}\right)\end{array}$ & $\begin{array}{c}\text { Mass } \\
(\mathbf{k g})\end{array}$ & $\begin{array}{c}\text { Critical } \\
\text { Load (kN) }\end{array}$ \\
\hline 7.60 & 15.21 & 2625.00 & 260.00 & $100,000.00$ & 0.00 & $47,209.88$ & 0.208 & 143.0 \\
\hline
\end{tabular}

\section{Conclusions}

This paper introduces a numerical procedure aimed to generate and optimize axial-symmetric hybrid (metal/composite) structures. The metallic part is supposed to be a lattice type structure, composted by elementary truss connected each other and manufactured by means of additive manufacturing process, while the composite parts are supposed to be integrated in the lattice structure by means of an automated filament winding process.

The developed procedure has been in the Ansys FEM code by means of the Ansys Design Parametric Language and can be interfaced with the optimization software ModeFrontier. Actually, Ansys has been adopted for the construction of the geometrical and the FE models, for the structural analysis and for the post-processing. ModeFrontier is dedicated to the definition of the best design set under defined loading and boundary conditions and thus to the optimization of the generate hybrid structure. The routine is able to generate autonomously a wide range of hybrid structures based on the lattice/skin concept.

A fundamental part of the whole routine is the generation of the unit cells repeated to fill the entire domain of definition of the metal lattice structure with strong connection (common nodes) to the external and internal skins. The connectivity of the unit cell can be easily managed by the user and/or by the optimization software. Another important aspect regards the adaptively of the lattice structure to the internal and external skin (the skins can be realized both in metallic and in composite material). 
In order to validate the numerical procedure and to check its robustness in generating differently shaped complex structures representative of the mechanical behaviour of lattice metallic structures with composite and metallic skins, several numerical test cases have been analyzed. The last test case has been optimized by fully exploiting all the functionality of the procedure in interfacing with the optimization software.

The analysed test cases have shown that the generated structures exhibit local buckling modes. In general, they have been found able to sustain from $25 \%$ to $15 \%$ additional compressive load before global buckling and loss of capability to sustain compressive load. Hence, for these structures, the buckling load of the unit cell can be considerably lower than the global buckling.

The results obtained for the last test-case have highlighted that, with the proposed routine, lattice/skin structures can be generated and optimised able to guarantee a reduction of about $55 \%$ in weight if compared to solid structures.

Author Contributions: All the authors contributed equally to this work.

Funding: This research received no external funding.

Conflicts of Interest: The authors declare no conflict of interest.

\section{References}

1. Tofail, S.A.; Koumoulos, E.P.; Bandyopadhyay, A.; Bose, S.; O'Donoghue, L.; Charitidis, C. Additive manufacturing: Scientific and technological challenges, market uptake and opportunities. Mater. Today 2018, 21, 22-37. [CrossRef]

2. Berman, B. 3-D printing: The new industrial revolution. Bus. Horiz. 2012, 55, 155-162. [CrossRef]

3. Wohlers, T. Wohlers Report 2014: Global Reports; Wohlers Associates: Fort Collins, CO, USA, 2014.

4. Wohlers, T. Wohlers Report 2015: Global Reports; Wohlers Associates: Fort Collins, CO, USA, 2015.

5. Levy, G.N.; Schindel, R.; Kruth, J.P. Rapid manufacturing and rapid tooling with layer manufacturing (LM) technologies, state of the art and future perspectives. CIRP Ann. 2003, 52, 589-609. [CrossRef]

6. Huang, S.H.; Liu, P.; Mokasdar, A.; Hou, L. Additive manufacturing and its societal impact: A literature review. Int. J. Adv. Manuf. Technol. 2013, 67, 1191-1203. [CrossRef]

7. Gao, W.; Zhang, Y.; Ramanujan, D.; Ramani, K.; Chen, Y.; Williams, C.B.; Wang, C.C.L.; Shin, Y.C.; Zhang, S.; Zavattieri, P.D. The status, challenges, and future of additive manufacturing in engineering. CAD Comput. Aided Des. 2015, 69, 65-89. [CrossRef]

8. Herzog, D.; Seyda, V.; Wycisk, E.; Emmelmann, C. Additive manufacturing of metals. Acta Mater. 2016, 117, 371-392. [CrossRef]

9. Olakanmi, E.; Cochrane, R.; Dalgarno, K. A review on selective laser sintering/melting (SLS/SLM) of aluminium alloy powders: Processing, microstructure, and properties. Prog. Mater. Sci. 2015, 74, 401-447. [CrossRef]

10. Thompson, M.K.; Moroni, G.; Vaneker, T.; Fadel, G.; Campbell, R.I.; Gibson, I.; Bernard, A.; Schulz, J.; Graf, P.; Ahuja, B.; et al. Design for Additive Manufacturing: Trends, opportunities, considerations, and constraints. CIRP Ann. Manuf. Technol. 2016, 65, 737-760. [CrossRef]

11. Dilberoglu, U.M.; Gharehpapagh, B.; Yaman, U.; Dolen, M. The role of additive manufacturing in the era of industry 4.0. Procedia Manuf. 2017, 11, 545-554. [CrossRef]

12. Wu, P.; Wang, J.; Wang, X. A critical review of the use of 3-D printing in the construction industry. Autom. Constr. 2016, 68, 21-31. [CrossRef]

13. ASTMF2792-12a. Standard Terminology for Additive Manufacturing Technologies; ASTM International: West Conshohocken, PA, USA, 2012.

14. Gibson, I.; Rosen, D.W.; Stucker, B. Additive Manufacturing Technologies: Rapid Prototyping to Direct Digital Manufacturing; Springer: New York, NY, USA, 2010.

15. Grenda, E. Printing the Future: The 3D Printing and Rapid Prototyping Sourcebook, 3rd ed.; Castle Island Co.: Arlington, MA, USA, 2009.

16. Kruth, J.P. Material Increase Manufacturing by Rapid Prototyping Techniques. CIRP Ann. Manuf. Technol. 1991, 40, 603-614. [CrossRef] 
17. Bhushan, B.; Caspers, M. An overview of additive manufacturing (3D printing) for microfabrication. Microsyst. Technol. 2017, 23, 1117-1124. [CrossRef]

18. Panesar, A.; Abdi, M.; Hickman, D.; Ashcroft, I. Strategies for functionally graded lattice structures derived using topology optimisation for additive manufacturing. Addit. Manuf. 2018, 19, 81-94. [CrossRef]

19. Ngo, T.D.; Kashani, A.; Imbalzano, G.; Nguyen, K.T.Q.; Hui, D. Additive manufacturing (3D printing): A review of materials, methods, applications and challenges. Compos. Part B Eng. 2018, 143, 172-196. [CrossRef]

20. Brooks, H.; Brigden, K. Design of conformal cooling layers with self-supporting lattices for additively manufactured tooling. Addit. Manuf. 2016, 11, 16-22. [CrossRef]

21. Gu, D.D.; Meiners, W.; Wissenbach, K.; Poprawe, R. Laser additive manufacturing of metallic components: Materials, processes and mechanisms. Int. Mater. Rev. 2012, 57, 133-164. [CrossRef]

22. Chua, C.K.; Leong, K.F.; Lim, C.S. Innovative Developments in Design and Manufacturing-Advanced Research in Virtual and Rapid Prototyping. In Rapid Prototyping: Principles and Applications, 3rd ed.; World Scientific Publishing Co Pte Ltd: Singapore, 2010; pp. 497-503.

23. Lee, H.; Lim, C.H.J.; Low, M.J.; Tham, N.; Murukeshan, V.M.; Kim, Y.-J. Lasers in additive manufacturing: A review. Int. J. Precis. Eng. Manuf. Green Technol. 2017, 4, 307-322. [CrossRef]

24. Mure, L.E.; Gaytan, S.M.; Ramirez, D.A.; Martines, E.; Hernandez, J.; Amato, K.N.; Shindo, P.W.; Medina, F.R.; Wicker, R.B. Metal Fabrication by Additive Manufacturing Using Laser and Electron Beam Melting Technologies. J. Mater. Sci. Technol. 2012, 28, 1-14. [CrossRef]

25. Rafi, H.K.; Karthik, N.V.; Gong, H.; Starr, T.L.; Stucker, B.E. Microstructures and mechanical properties of Ti6Al4V parts fabricated by selective laser melting and electron beam melting. J. Mater. Eng. Perform. 2013, 22, 3872-3883. [CrossRef]

26. Sing, S.L.; An, J.; Yeong, W.Y.; Wiria, F.E. Laser and electron-beam powder-bed additive manufacturing of metallic implants: A review on processes, materials and designs. J. Orthop. Res. 2016, 34, 369-385. [CrossRef]

27. Biamino, S.; Penna, A.; Ackelid, U.; Sabbadini, S.; Tassa, O.; Fino, P.; Pavese, M.; Gennaro, P.; Badini, C. Electron beam melting of Ti-48Al-2Cr-2Nb alloy: Microstructure and mechanical properties investigation. Intermetallics 2011, 19, 776-781. [CrossRef]

28. Tomlin, M.; Meyer, J. Topology optimization of an additive layer manufactured (ALM) aerospace part. In Proceedings of the 7th Altair CAE Technology Conference, Warwickshire, UK, 10 May 2011.

29. Krog, L.; Tucker, A.; Rollema, G. Application of topology, sizing and shape optimization methods to optimal design of aircraft components. In Proceedings of the 3rd Altair UK HyperWorks Users Conference, Coventry, UK, 11-12 November 2002.

30. Ferguson, I.; Frecker, M.; Simpson, T.W. Topology optimization software for additive manufacturing: A review of current capabilities and a real-world example. In Proceedings of the ASME 2016 International Design Engineering Technical Conferences and Computers and Information in Engineering Conference, Charlotte, CA, USA, 21-24 August 2016; American Society of Mechanical Engineers: New York, NY, USA, 2016.

31. Saadlaoui, Y.; Milan, J.-L.; Rossi, J.-M.; Chabrand, P. Topology optimization and additive manufacturing: Comparison of conception methods using industrial codes. J. Manuf. Syst. 2017, 43, 178-186. [CrossRef]

32. Chen, W.; Zheng, X.; Liu, S. Finite-Element-Mesh Based Method for Modeling and Optimization of Lattice Structures for Additive Manufacturing. Materials 2018, 11, 2073. [CrossRef] [PubMed]

33. Mahmoud, D.; Elbestawi, M.A. Lattice Structures and Functionally Graded Materials Applications in Additive Manufacturing of Orthopedic Implants: A Review. J. Manuf. Mater. Process. 2017, 1, 13. [CrossRef]

34. Jiang, J.; Xu, X.; Stringer, J. Support Structures for Additive Manufacturing: A Review. J. Manuf. Mater. Process. 2018, 2, 64. [CrossRef]

35. Ferro, C.G.; Varetti, S.; Vitti, F.; Maggiore, P.; Lombardi, M.; Biamino, S.; Manfredi, D.; Calignano, F. A Robust Multifunctional Sandwich Panel Design with Trabecular Structures by the Use of Additive Manufacturing Technology for a New De-Icing System. Technologies 2017, 5, 35. [CrossRef]

36. Cooper, K.; Steele, P.; Cheng, B.; Chou, K. Contact-Free Support Structures for Part Overhangs in Powder-Bed Metal Additive Manufacturing. Inventions 2018, 3, 2. [CrossRef]

37. Williams, C.B.; Cochran, J.K.; Rosen, D.W. Additive manufacturing of metallic cellular materials via three-dimensional printing. Int. J. Adv. Manuf. Technol. 2011, 53, 231-239. [CrossRef]

38. Rosen, D.W. Computer-aided design for additive manufacturing of cellular structures. Comput. Aided Des. Appl. 2007, 4, 585-594. [CrossRef] 
39. Deshpande, V.S.; Fleck, N.A.; Ashby, M.F. Effective properties of the octet-truss lattice material. J. Mech. Phys. Solids 2001, 49, 1747-1769. [CrossRef]

40. Zhang, Y.; Bernard, A.; Gupta, R.K.; Harik, R. Evaluating the design for additive manufacturing: A process planning perspective. Procedia CIRP 2014, 21, 144-150. [CrossRef]

41. Riccio, A.; Raimondo, F.; Sellitto, A.; Carandente, V.; Scigliano, R.; Tescione, D. Optimum design of ablative thermal protection systems for atmospheric entry vehicles. Appl. Therm. Eng. 2017, 119, 541-552. [CrossRef]

42. Vaissier, B.; Pernot, J.-P.; Chougrani, L.; Véron, P. Genetic-algorithm based framework for lattice support structure optimization in additive manufacturing. CAD Comput. Aided Des. 2018, 110, 11-23. [CrossRef]

43. Sellitto, A.; Borrelli, R.; Caputo, F.; Riccio, A.; Scaramuzzino, F. Application to plate components of a kinematic global-local approach for non-matching finite element meshes. Int. J. Struct. Integr. 2012, 3, 260-273. [CrossRef]

44. Sellitto, A.; Borrelli, R.; Caputo, F.; Riccio, A.; Scaramuzzino, F. Methodological approaches for kinematic coupling of non-matching finite element meshes. Procedia Eng. 2011, 10, 421-426. [CrossRef]

45. Ferrigno, A.; Di Caprio, F.; Borrelli, R.; Auricchio, F.; Vigliotti, A. The mechanical strength of Ti-6Al-4V columns with regular octet microstructure manufactured by electron beam melting. Materialia 2019, 5 . [CrossRef]

46. Ahmadi, S.; Campoli, G.; Yavari, S.A.; Sajadi, B.; Wauthle, R.; Schrooten, J.; Weinans, H.; Zadpoor, A. Mechanical behavior of regular open-cell porous biomaterials made of diamond lattice unit cells. J. Mech. Behav. Biomed. Mater. 2014, 34, 106-115. [CrossRef]

47. Dong, L.; Wadley, H. Mechanical properties of carbon fiber composite octet-truss lattice structures. Compos. Sci. Technol. 2015, 119, 26-33. [CrossRef]

(C) 2019 by the authors. Licensee MDPI, Basel, Switzerland. This article is an open access article distributed under the terms and conditions of the Creative Commons Attribution (CC BY) license (http://creativecommons.org/licenses/by/4.0/). 